\title{
Captura da Aceitação do Blackboard e do Tipo de Motivação de Alunos de Cursos Presenciais de Ciências Exatas em uma Universidade Privada
}

\author{
Capture of Blackboard Acceptance and Motivation Type of Exact Science Face-to-Face \\ Students at a Private University
}

Natália J. S. de Oliveira Escola de Ciência e TecnologiaUniversidade do Grande RioRio de Janeiro - RJ - Brasil natalia_joana@unigranrio.edu.br

\section{Thiago B. Procaci}

Pesquisador Independente

thiagoprocaci@gmail.com
Sean W. M. Siqueira

Programa de Pós-Graduação em Informática - Universidade Federal do Estado do Rio de Janeiro - Rio de Janeiro - RJ - Brasil sean@uniriotec.br

\section{Resumo}

A motivação tem sido objeto de estudo em diversas áreas de conhecimento. No que diz respeito a aceitação e uso de tecnologias, a motivação pode ser considerada um fator crucial, influenciando diretamente na decisão do usuário em utilizar ou não um sistema de informação. Embora existam modelos propostos com o intuito de compreender a aceitação e o uso de tecnologias, seus aspectos motivacionais não são totalmente explorados. O objetivo deste trabalho é identificar o tipo de motivação e os fatores que levam à aceitação e uso de um Ambiente Virtual de Aprendizagem (AVA), permitindo assim que a instituição desenvolva estratégias de intervenção. Para isto, foi proposto um questionário baseado no Modelo TAM3 (Technology Acceptance Model 3) e na Teoria da Autodeterminação. O questionário foi aplicado com alunos de cursos presenciais de Ciências Exatas de uma universidade privada que utiliza o Blackboard como AVA. Os resultados revelam que os alunos estão satisfeitos com os recursos educacionais e técnicos disponíveis para o uso do AVA e com sua aplicabilidade em sua área de conhecimento. Além disso, acreditam que a utilização do AVA melhora o seu desempenho na realização de suas atividades. Em relação à motivação, os resultados confirmam que os alunos se encontram mais motivados extrinsecamente do que intrinsecamente, ou seja, utilizam o AVA por obrigação e não por prazer ou vontade própria.

Palavras-Chave: Motivação, Blackboard, Aceitação e Uso de Tecnologia, Modelo TAM3, Teoria da Autodeterminação.

\begin{abstract}
Motivation has been subject of study in different knowledge areas. Regarding the acceptance and use of technology, motivation may be considered crucial, directly influencing users' decisions about using or not an information system. Although there exist models proposed for evaluating acceptance and use of technology, motivational aspects are not fully exploited. The objective of this work is to identify motivation type and factors that influence the acceptance and use of a Virtual Learning Environment (VLE). Then we proposed a questionnaire based on the TAM3 (Technology Acceptance Model 3) and the Self-Determination Theory. The questionnaire was used in a survey conducted with students of Exact Science face-to-face courses of a private university that adopts Blackboard as VLE. The results reveal that students are satisfied with organizational and technical resources available for VLE utilization, as long as their applicability on students' knowledge area. Besides, they believe that VLE utilization improves their performance during activities' execution. Regarding motivation, the results confirm the students are more extrinsically motivated than intrinsically, which means they use the VLE due to obligation and not for pleasure or free will.
\end{abstract}

Keywords: Motivation, Blackboard, Acceptance and Use of Technology, Model TAM3, Self-Determination Theory.

Cite as: Oliveira, N. J. S., Procaci, T. B., \& Siqueira, S. W. M. (2020). Capture of Blackboard Acceptance and Motivation Type of Exact Science Face-to-Face Students at a Private University (Captura da Aceitação do Blackboard e do Tipo de Motivação de Alunos de Cursos Presenciais de Ciências Exatas em uma Universidade Privada). Brazilian Journal of Computers in Education (Revista Brasileira de Informática na Educação - RBIE), 28, 229-259. DOI: 10.5753/RBIE.2020.28.0.229 


\section{Introdução}

As tecnologias de informação e comunicação (TICs) estão cada vez mais presentes nas salas de aula, fazendo com que o método de aprender e ensinar seja repensado e possivelmente se torne mais atraente, diversificado, criativo, colaborativo, cooperativo e acessível (Oliveira e Moura, 2015). As Instituições de Ensino Superior (IES) vêm utilizando um conjunto de ferramentas (TICs) que dê suporte à execução de atividades pelos alunos e que seja capaz de promover a interação entre alunos, professores e tutores. Geralmente, um Ambiente Virtual de Aprendizagem (AVA) agrega este conjunto de ferramentas e portanto as IES estão adotando cada vez mais AVAs em seus cursos (Moran, 2007).

No contexto dos Sistemas de Informação (SI), a motivação pode influenciar diretamente a satisfação do usuário e, consequentemente, a sua decisão de utilizar ou não um determinado sistema. Delone e Mclean (2003) mostraram através de seus estudos que "Motivação" e "Modelo de Aceitação e Uso de Tecnologias" estão intimamente ligados aos SIs, uma vez que "uma experiência positiva do uso levará a uma maior satisfação do usuário, da mesma forma que o aumento da satisfação do usuário levará ao aumento da intenção de usar e, assim, usar." Ainda segundo os autores, "intenção de usar" refere-se a atitude, enquanto "uso" refere-se a comportamento, logo uma experiência negativa do uso pode levar à descontinuidade do sistema.

Modelos relacionados à motivação, bem como à aceitação e ao uso de tecnologias, podem ser aplicados em diversas áreas do conhecimento, inclusive na Educação, desde que sejam devidamente adaptados ${ }^{1}$. Existem diversos trabalhos onde modelos de aceitação e uso de tecnologia foram aplicados na Educação (Roca e Gagné (2008); Prieto et al. (2014); Hsu et al., (2016)), porém são poucos os que exploram as questões motivacionais empregadas em tais modelos. Em geral, os modelos de aceitação e uso de tecnologias mais utilizados tratam a questão motivacional de forma superficial, ou seja, em muitas das vezes, ela se encontra implícita nas variáveis que os compõem. De acordo com Venkatesh (2000) e Pereira (2018), o potencial da motivação intrínseca para melhorar o uso e aceitação do usuários tem sido pouco explorado na área de SI, mesmo sendo considerada importante na adoção de um sistema e tendo como vantagem a sua durabilidade no decurso do tempo, ou seja, a motivação intrínseca tende a manter-se ao longo do tempo.

Assim, o objetivo deste trabalho é identificar os fatores e o tipo de motivação que influenciam a aceitação e o uso de um AVA através da combinação da Teoria da Autodeterminação (SDT Self-Determination Theory) com o Modelo de Aceitação de Tecnologia 3 (TAM3 - Technology Acceptance Model 3).

A Teoria da Autodeterminação (Ryan e DECI, 2000a) é uma das teorias que auxiliam na compreensão da motivação e é a amplamente utilizada e referenciada quando se discute motivação (Chen e Jang, 2010, Dupuy et al., 2016, Hew et al., 2016, Lee et al., 2015). Além disso, ela se destaca das outras teorias motivacionais existentes (Herzberg, 1968, Macgregor, 1960, Maslow, 1943, Vroom, 1964) devido ao processo de internalização. De acordo com Ryan e Deci (2000a), "quanto mais internalizamos e assimilamos as razões de uma ação, mais nossas ações extrinsecamente motivadas se tornam autodeterminadas”.

A escolha do TAM3 se deve ao fato dele ser o mais completo em relação às questões motivacionais. Nele foi inserido o constructo "Diversão", que, segundo os autores, representa a

\footnotetext{
${ }^{1}$ Os modelos de aceitação e uso de tecnologias são gerais para qualquer tipo de tecnologia. Ao utilizar os questionários propostos para uso geral em um uso específico, é necessário adaptar os questionários para refletir a realidade da tecnologia específica que se deseja analisar.
} 
motivação intrínseca em relação ao uso e aceitação de um sistema (Venkatesh e Bala, 2008). Porém, Howard et al., (2010) afirmam que no modelo TAM3 a motivação intrínseca vai muito além da constructo "Diversão", pois a mesma encontra-se presente, mesmo que implicitamente, na maioria de seus constructos.

Por mais que o Modelo TAM3 contemple aspectos motivacionais, o mesmo não é suficiente para determinar o tipo de motivação que leva ou não um usuário a aceitar e usar um determinado sistema, pois trata explicitamente apenas da motivação intrínseca, desconsiderando a motivação extrínseca e a desmotivação. Por isso, após um estudo da literatura com o objetivo de alcançarmos melhor entendimento dos conceitos inerentes aos diversos modelos e teorias existentes, sentimos a necessidade de combinar o TAM3 com à SDT (Deci e Ryan, 1985; Ryan e Connell, 1989).

A combinação do TAM3 com a SDT facilita a mensuração dos efeitos de determinadas variáveis e o entendimento dos motivos que levam o aluno a aceitar e usar um AVA. Deste modo, um questionário foi elaborado e aplicado a um grupo de alunos da área de Ciências Exatas que utiliza o Blackboard ${ }^{2}$ como AVA em uma universidade privada. A escolha por este grupo de alunos, o AVA e a IES se deram por questões de apoio institucional e facilidade de acesso para a realização do estudo. Os resultados mostraram que tal combinação se mostrou eficaz em relação à detecção do tipo de motivação relacionado à aceitação e uso do AVA em questão, além de contribuir com uma visão mais ampla sobre o processo de internalização que, neste cenário, vai perdendo espaço para a regulação externa, indicando que o uso não está vinculado ao prazer ou à vontade própria. Em relação a confiabilidade dos itens que compõem os constructos do TAM3, os resultados se mostraram satisfatórios, pois a maioria dos constructos obteve valores aceitáveis, indicando um alto grau de consistência interna. Para reduzir o problema de baixa correlação entre os itens de alguns constructos, foi utilizada uma técnica chamada "purificação de escala".

Este artigo é organizado da seguinte forma: a seção 2 apresenta os conceitos de motivação intrínseca e extrínseca sob o prisma da SDT e descreve sucintamente o TAM e as suas variações; a seção 3 apresenta uma revisão sistemática na literatura, a fim de identificar trabalhos que utilizem a combinação SDT e TAM3, como proposto neste artigo; a seção 4 apresenta a descrição do questionário utilizado; a seção 5 descreve os resultados obtidos; a seção 6 apresenta a validação de confiabilidade dos constructos referentes ao modelo TAM3; a seção 7 apresenta as limitações do trabalho e ameaças ao método aplicado e a seção 8 apresenta as conclusões e os trabalhos futuros.

\section{Modelo de Aceitação de Tecnologia (TAM) e Teoria da Autodeterminação (SDT)}

Esta seção descreve as bases para este trabalho, são elas: os constructos que compõem o Modelo de Aceitação de Tecnologia (TAM3) e os tipos motivação presentes na Teoria da Autodeterminação (SDT).

\subsection{Variações do Modelo TAM}

Os modelos de uso e aceitação de tecnologias vêm sendo amplamente estudados e aplicados em todo o mundo desde 1989. De acordo com Oliveira e Martins (2011) e Oliveira (2019), os modelos e teorias mais utilizados são (siglas em inglês): Modelo de Aceitação de Tecnologia - TAM

\footnotetext{
2 http://www.blackboard.com/index.html

Foi implantado recentemente na Instituição, que resolveu investir em cursos de capacitação para que seus professores pudessem explorar da melhor maneira possível os recursos que o ambiente tem a oferecer.
} 
(Davis, 1989); Teoria do Comportamento Planejado - TPB (Ajzen, 1991); Teoria Unificada de Aceitação e Uso de Tecnologia - UTAUT (Venkatesh et al., 2003); Teoria da Difusão da Inovação - DOI (Rogers, 1995); e Tecnologia, Organização e Ambiente - TOE (Tornatzky et al., 1990). Além de ser o mais amplamente adotado, o TAM considera aspectos relacionados à motivação desde sua primeira versão.

O modelo TAM foi desenvolvido em 1989 tendo como base a Teoria da Ação Racionalizada (TRA - Theory of Reasoned Action), que é uma das mais importantes e influentes teorias do comportamento humano (Fishbein e Ajzen, 1975). O modelo tem como objetivo entender o que leva um indivíduo a aceitar ou rejeitar a Tecnologia da Informação (TI). Ele é formado por dois constructos teóricos que são considerados os determinantes fundamentais para o uso de um sistema (Davis, 1989), são eles: Utilidade Percebida (PU - Perceived Usefulness) que define o grau em que uma pessoa acredita que utilizar determinado sistema melhora o seu desempenho nas atividades; e Facilidade de Uso Percebida (PEOU - Perceived Ease of Use) que define o grau em que uma pessoa acredita que a utilização de determinado sistema será fácil.

Onze anos depois, Venkatesh e Davis (2000) resolveram estender o TAM, originando o TAM2, que inclui novos constructos que detalham melhor a Utilidade Percebida em termos de processo de influência social (norma subjetiva, voluntariedade e imagem) e processos instrumentais cognitivos (relevância no trabalho, qualidade de resultados, demonstrabilidade do resultado e facilidade de uso percebida) (Venkatesh e Davis, 2000). Além dos novos constructos, também foram incluídos no modelo TAM2 duas variáveis moderadoras: Experiência e Voluntariedade. A "Experiência” influencia tanto na "Norma Subjetiva” em relação à "Intenção Comportamental" (Intenção de Uso) quanto na "Norma Subjetiva” em relação à "Utilidade Percebida”. Os autores alegam que existem "teorias e evidências que sugerem que o efeito direto da norma subjetiva sobre as intenções pode diminuir com o passar do tempo, com o aumento da experiência do sistema” (Venkatesh e Davis, 2000). Por sua vez, a "Voluntariedade” influencia na "Norma Subjetiva” em relação à “Intenção de Uso”. Ela é utilizada para distinguir entre o uso obrigatório e voluntário do sistema. Vale ressaltar que a intenção de utilização de um novo sistema, mesmo que obrigatório, pode variar pois alguns usuários podem não estar dispostos a utilizá-lo (VENKATESH, DAVIS, 2000).

O modelo TAM3, proposto por Venkatesh e Bala (2008), surgiu da combinação entre o modelo TAM2 e modelo dos determinantes da facilidade de uso percebida (Venkatesh, 2000). Esta versão inclui novos constructos que detalham a Facilidade de Uso Percebida. Os constructos são: controle (interno e externo - definidos como "auto eficácia no computador” e "percepção de controle externo”, respectivamente), motivação intrínseca (definida como “diversão") e emoção (definida como "ansiedade em utilizar o computador”). Além disso, Venkatesh (2000) também considera importante para este novo modelo a inclusão de constructos de ajuste: a "usabilidade objetiva” e o "prazer percebido. Ainda nesta versão, os autores testaram relações entre variáveis que não haviam sido testadas nos modelos anteriores. Oliveira e Siqueira (2018) detalham melhor os novos constructos inseridos nos modelos TAM2 e TAM3.

Davis (1989) relata que a motivação intrínseca estava começando a ser reconhecida já na primeira versão do TAM como um mecanismo de grande potencial por trás da aceitação pelo usuário. Dentre todos os modelos TAM, o TAM3 é o que trata mais explicitamente as questões motivacionais e, por isso, fundamenta este trabalho. Entretanto, como exposto na Seção 1, o TAM3 ainda desconsidera a motivação extrínseca e a desmotivação. 


\subsection{Teoria da Autodeterminação (SDT)}

Ao contrário da maioria das teorias de motivação existentes (Herzberg, 1968; MacGregor, 1960; Maslow, 1943; Vroom, 1964), a SDT não considera a motivação como um fenômeno unitário (motivado ou desmotivado). Ela foi elaborada em 1981 e para seus autores, a motivação pode variar não apenas no nível de motivação, mas também no tipo de motivação, sendo a mais comum a distinção que se faz entre a motivação intrínseca e a motivação extrínseca (Deci e Ryan, 1985). A motivação intrínseca ocorre quando a pessoa se motiva por ela mesma, ou seja, pelo seu próprio interesse (auto motivada). A extrínseca, por outro lado, ocorre quando a pessoa é motivada por recompensas ou outros estímulos externos (Ryan e Deci, 2000a). De Oliveira et al. (2018) apresentam uma discussão sobre como combinar diferentes teorias relacionadas à motivação.

A SDT especifica diferentes tipos de motivação, sendo baseada nas diferentes razões que dão origem a uma ação. Por exemplo, "um aluno pode ser altamente motivado para fazer trabalhos de casa por curiosidade e interesse ou porque ele quer obter a aprovação de um professor ou de seus pais”. Neste exemplo, a quantidade de motivação não varia, mas a natureza e o foco da motivação são evidentes (Ryan e Deci, 2000a). Para entender melhor a distinção entre as motivações, os autores desenvolveram um continuum, chamado de Continuum da Autodeterminação, que detalha as “diferentes formas de motivação extrínseca e os fatores contextuais que promovem ou impedem a internalização e a integração da regulação para esses comportamentos”, que podem variar entre desmotivação, motivação extrínseca e motivação intrínseca. Oliveira e Siqueira (2018) ilustram e descrevem em detalhes o Continuum da Autodeterminação, a taxonomia da motivação humana e os estilos regulatórios, baseados em Ryan e Deci (2000a).

\subsubsection{Motivação Extrínseca}

De uma forma geral, a motivação extrínseca é aquela onde o indivíduo é movido a fazer algo por recompensas externas, pois a ação por si só não o satisfaz. Este tipo de motivação é dividido em quatro partes, tem sido organizado desta forma justamente para refletir seus diferentes graus de autonomia ou de autodeterminação. A diferença entre eles se dá pelo processo de internalização, que pode ser por razões externas, introjetadas, identificadas ou integradas (Ryan e Deci, 2000a):

- A categoria de regulação externa é a forma menos autônoma de motivação, pois se encontra mais próxima da desmotivação que os demais tipos. Nesse caso, o indivíduo age somente em prol de recompensas ou até mesmo para evitar punições.

- A categoria de regulação introjetada é aquela onde o indivíduo administra as consequências externas mediante o resultado de pressões internas como culpa e ansiedade.

- A categoria de regulação identificada é aquela onde o indivíduo se identifica com o objetivo, percebe a importância na realização de uma determinada tarefa, ou seja, existe uma interiorização, mesmo que o motivo para fazê-la ainda seja externo.

- A categoria de regulação integrada é a forma mais autônoma de motivação extrínseca, se encontrando mais à direita do continuum. Embora o foco ainda esteja "nos benefícios pessoais advindos da realização da atividade”.

Para Deci e Ryan, 1985; Ryan e Deci 2000b apud Appel-Silva et al. (2011, p. 9)

“a importância do estudo dessas categorias de motivação, segundo a SDT, é pelo fato de que a pessoa com uma internalização de valores mais consistente demonstra uma motivação mais integrada ao seu Eu e, portanto, revela comportamentos mais efetivos, melhor inserção grupal, maior persistência, bem como lida melhor com os fracassos eventuais, além da tendência em apresentar maior saúde e bem-estar psicológico”. 
Pode-se concluir então que ações extrinsecamente motivadas se tornam autodeterminadas quando o indivíduo internaliza as razões e as assimila ao Eu (Ryan e Deci, 2000a).

\subsubsection{Motivação Intrínseca}

A motivação intrínseca é o oposto da motivação extrínseca, pois ela é definida como a realização de uma atividade por satisfações próprias e não por recompensas externas. O indivíduo motivado intrinsicamente tem interesse e prazer na realização da tarefa em si, ou seja, seu envolvimento é puramente espontâneo.

Vale ressaltar que as pessoas são intrinsecamente motivadas de formas diferentes, ou seja, aquilo que motiva um determinado indivíduo não necessariamente motivará outro indivíduo. Mesmo que a motivação intrínseca exista “dentro" dos indivíduos, existe uma motivação intrínseca entre o indivíduo e a atividade, ou seja, nem sempre todos os indivíduos estarão intrinsecamente motivados para a realização de uma tarefa específica (Ryan e Deci, 2000a).

No que se refere à Educação, a motivação, o engajamento, a diversão e muitas outras emoções positivas são essenciais durante o processo de ensino e aprendizagem. De acordo com a SDT, se aumentarmos a motivação dos alunos, eles terão melhor desempenho e conseguirão aprender mais, principalmente se essa motivação for a intrínseca (Kirschner e Neelen, 2016). Por esses motivos, além de complementar o questionário do TAM3 com questões da SDT, também sentimos a necessidade de incluir questões (descritas na seção 4) que nos levassem a entender o que falta no AVA para torná-lo mais atrativo segundo a visão dos alunos. O objetivo é identificar se falta mais interação, elementos de ludificação (ou gamificação, como encontrado na literatura), associação com redes sociais, materiais multimídias, entre outros. Tais questões foram elaboradas pelos autores e encontram-se disponíveis no Apêndice. Diante dos resultados, a instituição em questão poderá gerar planos de ação (intervenções) para engajar mais os seus alunos durante o processo de ensino e aprendizagem através do AVA.

\section{Revisão Sistemática da Literatura}

O TAM vem sendo amplamente estudado na área de e-learning. Abdullah e Ward (2016) realizaram uma revisão sistemática a fim de identificar os fatores externos mais comuns nos trabalhos que ampliaram o modelo TAM para sustentar a aceitação ou o uso do e-learning no período de 2008-2018. Foram identificados 152 fatores externos diferentes em 107 trabalhos. Dentre os fatores, apenas cinco foram encontrados em dez ou mais estudos e por isso foram considerados os mais comuns. São eles: auto eficácia, norma subjetiva, prazer, ansiedade por usar o computador e experiência.

Lin et al. (2014) e Ramirez-Anormaliza et al. (2015) utilizaram o TAM para investigar a aceitação de AVAs. Mbarek e Zaddem (2013) e Zanini (2016) utilizaram como base o modelo TAM para identificar a importância da interação no ambiente de $e$-learning. Al-sayyed (2015) e Balog (2015) utilizaram o TAM3 para investigar a aceitação do e-learning em universidades.

Nota-se, entretanto, que nenhum destes trabalhos utilizou a SDT. Deste modo, decidimos explorar a fundo a literatura no contexto da utilização do modelo TAM juntamente com a Teoria da Autodeterminação. Para isso, foi realizada uma Revisão Sistemática da Literatura (RSL) no período compreendido entre os anos de 2008 (ano de publicação do TAM3) e 2018. De acordo com Kitchenham e Charters (2007), uma RSL é uma pesquisa aprofundada que visa a identificar e sintetizar trabalhos existentes na literatura para uma determinada "questão de pesquisa, área de tópico ou fenômeno de interesse”. 


\subsection{Protocolo de Busca}

A busca dos artigos relacionados ao assunto foi feita em quatro grandes bases de dados eletrônicos: ACM Digital Library ${ }^{3}$, IEEE Xplore ${ }^{4}$, Elsevier (Computers in Human Behavior e Computers \& Education $)^{5}$ e Google Acadêmico ${ }^{6}$. Para isso, foi utilizada a seguinte string de busca:

\section{(((TAM3 Model) OR TAM Model) AND Self-Determination Theory)}

Esta combinação de palavras-chaves foi a que se mostrou mais eficaz na busca de artigos, com base em um conjunto de trabalhos utilizados para verificação dos resultados de busca, dentre os que utilizassem qualquer variação do modelo TAM juntamente com a SDT, assim como proposto neste trabalho. Não foram inseridos na string os termos "e-learning”, "ambiente virtual de aprendizagem” e seus acrônimos e termos relacionados, pois, de acordo com as análises de consultas realizadas, tal inclusão restringiu os resultados a ponto de excluir artigos importantes utilizados como base de verificação dos resultados.

Os autores optaram pelas bibliotecas digitais da ACM e IEEE por serem consideradas os principais fóruns de artigos da área de Computação. Na Elsevier, as buscas retornavam muitos trabalhos não relacionados, de modo que optou-se restringir a consulta aos periódicos Computers in Human Behavior e Computers \& Education por serem referências em Informática na Educação. Finalmente, o Google Acadêmico foi escolhido pelo fato de contemplar diversas outras bases de dados e, deste modo, ser possível ter ótima cobertura dos trabalhos nos assuntos desejados.

Para facilitar a seleção de trabalhos, foram definidos alguns critérios de inclusão e exclusão a fim de garantir a seleção dos estudos relevantes. O processo de seleção de trabalhos foi divido em três etapas, descritas a seguir:

- $\quad 1^{\text {a }}$ etapa: download dos artigos que satisfizeram a string adotada e os seguintes critérios de inclusão:

o Período: 2008 - 2018;

o Artigos disponíveis na íntegra para download. Para isso, foi utilizado o proxy de uma IES pública federal com base nos periódicos da CAPES;

o Artigos de conferências e periódicos, teses e dissertações.

Nesta etapa foi obtido um total de 256 trabalhos.

- $\quad 2^{\text {a }}$ Etapa: Após o download dos trabalhos, foi feito um segundo filtro com o objetivo de pré-selecionar os que se mostrassem mais relevantes, baseando-se nos seguintes critérios de inclusão e exclusão:

o Inclusão:

- Idioma: Inglês;

- Trabalhos com cinco ou mais páginas.

o Exclusão:

- Trabalhos duplicados;

- Artigos que se mostraram não relevantes após a leitura dos resumos, introduções e conclusões dos artigos.

\footnotetext{
${ }^{3}$ http://dl.acm.org/

${ }^{4}$ http://ieeexplore.ieee.org/Xplore/home.jsp

${ }^{5}$ https://www.elsevier.com/search?query=pain

${ }^{6}$ https://scholar.google.com.br/
} 
Ao final desta etapa, foram selecionados 37 trabalhos do total de 256 recuperados na etapa anterior.

- $\quad 3^{a}$ Etapa: Dos 37 trabalhos pré-selecionados, apenas 16 foram considerados relevantes e lidos completamente.

o Exclusão:

- Trabalhos que não contemplavam a combinação da SDT com o Modelo TAM.

Ao final desta etapa, obtivemos um total de 16 trabalhos. Com o intuito de melhorar e validar o resultado da revisão sistemática, foi realizado um procedimento conhecido como "snowballing". Tal procedimento examina a lista de referências dos artigos selecionados em busca de outras publicações relevantes ao tema. Existem dois tipos de "snowballing”, o "backward snowballing” que utiliza a lista de referências dos artigos selecionados para identificar novas publicações e o "foward snowballing" que identifica novas publicações a partir dos documentos que citam o artigo que está sendo examinado. Cabe ao autor decidir se utilizará os dois ou um único procedimento (Kalus, Kuhrmann, 2013, Wohlin, 2014, 2016).

Neste artigo, foi a aplicado o procedimento "backward snowballing” nos dezesseis artigos recuperados na RSL, além disso, também foi levado em consideração as demais publicações dos autores. Ao final, foram recuperados nove trabalhos, porém somente dois foram considerados relevantes e lidos completamente. Os demais artigos foram descartados baseando-se nos mesmos critérios de inclusão e exclusão aplicados na RSL. Os 16 trabalhos selecionados são descritos na seção 3.2.

\subsection{Seleção dos Trabalhos Relacionados}

A RSL mostrou que a combinação entre TAM e SDT vem sendo explorada na literatura em diferentes contextos como, por exemplo, para verificar a aceitação de dispositivos móveis (Nikou e Economides, 2014a, 2014b, 2017), para explorar os fatores que levam ao compartilhamento proativo de conhecimento, ou seja, a motivação natural para compartilhar conteúdo (Kang et al., 2017), para avaliar o impacto das motivações no contexto de serviços de redes sociais baseados em localização (Sun et al., 2015), para avaliar a adoção de Tecnologia de Informação (TI) Verde ${ }^{7}$ (Wati e Koo, 2012), para compreender melhor os fatores motivacionais que podem afetar as atitudes e comportamentos dos indivíduos em utilizar diferentes redes sociais (coorporativas e públicas) (Xiong et al., 2014), e para verificar quais são os fatores determinantes para envolvimento do consumidor com um aplicativo de m-commerce (Mclean, 2018). Cheng et al. (2016) utilizaram esta combinação para criar um modelo de motivação capaz de classificar e, assim, identificar as motivações dos usuários no contexto de "economia compartilhada" (e.g., aluguel, empréstimo, permuta) através de uma plataforma digital. Akhlaq e Ahmed (2013) os combinaram para identificar se os fatores motivacionais extrínsecos e intrínsecos aumentam ou diminuem a confiança para a adoção do internet banking. Lee et al (2013) utilizaram o modelo TAM e os principais fatores motivacionais para analisar os efeitos das motivações intrínsecas e extrínsecas na aceitação do BIM (Building Information Modeling). BIM é definido como "uma nova abordagem para gerenciamento de projeto, construção e instalações, na qual uma representação digital do processo de construção, é usada, para facilitar a troca e a interoperabilidade de informações em formato digital" (Lee et al., 2013).

No contexto educacional, a combinação TAM/SDT também está presente. Roca e Gagné (2008) propuseram uma extensão do TAM no contexto de $e$-learning a fim de analisar as relações

\footnotetext{
${ }^{7}$ TI Verde se refere ao conjunto de técnicas, práticas e princípios para tornar o uso de tecnologia mais sustentável e menos prejudicial ao meio ambiente.
} 
entre as variáveis da SDT e as variáveis do TAM e avaliar a intenção dos usuários em continuar ou não a fazer cursos de e-learning fora do ambiente de trabalho. Para isto, introduziram "Autonomia", "“Competência” e "Pertencimento" (relação) como determinantes da utilidade percebida, da ludicidade percebida e da facilidade de uso percebida. Prieto et al. (2014) também ampliaram o TAM com constructos de outras teorias para avaliar a aceitação de tecnologias móveis, tendo professores como foco. Hsu et al., (2016) integraram o modelo TAM à SDT e à "Influência Social” para desenvolver um modelo capaz de avaliar a intenção contínua de usar um sistema de tutoria intitulado como e-tutoria. O uso da SDT também foi baseado na Escala de Satisfação de Necessidades Básicas, ou seja, na "Autonomia”, na "Competência” e no "Pertencimento". Joo et al. (2018) combinaram o TAM e a SDT para compreender melhor a aceitação, a motivação e a participação continuada dos alunos de uma universidade coreana que receberam créditos para utilizarem MOOCs (Massive Open Online Courses). No modelo proposto pelos autores, a "Autodeterminação", a "Utilidade Percebida” e a "Facilidade de Uso Percebida" estão associadas a satisfação e o objetivo é examinar como essas variáveis afetam a intenção de continuidade dos estudantes.

No intuito de avaliar os principais fatores que levam a adoção de um AVA (no artigo é utilizado o termo Sistema de Gerenciamento de Aprendizagem ou mais especificamente Learning Management System - LMS) por parte dos tutores de uma instituição de nível superior na Palestina, Abdallah et al. (2016) desenvolveram uma abordagem multidimensional que integra o modelo de sucesso de SI de Delone e Mclean (2003), o modelo TAM e a SDT. Seu objetivo em relação à SDT é examinar a motivação intrínseca subjacente, pois os pesquisadores afirmam que “a motivação extrínseca perdeu seu papel dominante na motivação intrínseca”, no contexto local.

Nikou e Economides (2016) utilizaram a combinação do TAM com a SDT para avaliar o impacto do uso de dispositivos móveis durante uma atividade de aprendizagem externa. Neste cenário, foi realizada uma atividade avaliativa ao ar livre durante um projeto de educação ambiental. Os autores também avaliaram o impacto que esse tipo de atividade de aprendizagem e avaliação ao ar livre exerce sobre a motivação dos alunos. Porém, levaram em consideração apenas as três necessidades básicas pertencentes à SDT. Howard et al., (2010) afirmam que o TAM simplifica e trivializa o conceito de motivação, o que dificulta possíveis intervenções para melhorar a adoção e uso de tecnologias. Diante disso, os autores redefinem no TAM3 o conceito de motivação, explorando a motivação intrínseca que existe por trás das variáveis do TAM.

O grande diferencial de nosso estudo em comparação aos já existentes é a utilização do modelo TAM3 combinado com a SDT especificamente para avaliar a aceitação e o uso de AVA e as questões motivacionais subjacentes ao uso e aceitação do AVA em questão. Além disso, o questionário utilizado também foi complementado com questões relacionadas a jogos, interação e ludificação, com o intuito de compreender outros aspectos motivacionais que podem influenciar diretamente no uso e aceitação do AVA por parte dos alunos. A ludificação consiste na utilização de elementos de jogos (e.g., troféus, medalhas, avatar) em ambientes fora do contexto de jogos com o objetivo de motivar os indivíduos a uma determinada ação, auxiliar na solução de problemas e promover aprendizagem (Deterding e Dixon, 2011; Werbach e Hunter, 2012). Os elementos de jogos também podem ser classificados como intrínsecos e extrínsecos, como pode ser visto no trabalho de Lopes et al. (2015). Vale ressaltar que não foi encontrado na RSL nenhum trabalho que utilizasse a combinação entre o modelo TAM3 e a SDT, como proposto neste artigo. Os trabalhos encontrados que utilizaram a combinação do TAM com a SDT avaliaram apenas a Escala de Satisfação de Necessidades Básicas e os conceitos de motivações extrínsecas e intrínsecas de forma muito abstrata. Por outro lado, este trabalho contempla os tipos de motivação e o processo de internalização, que formam a base da teoria da autodeterminação. Deste modo, a abordagem proposta possibilita um entendimento do tipo de motivação e, portanto, do que leva o aluno a usar ou não o AVA. 


\section{Descrição do Questionário Aplicado}

A fim de avaliar a aceitação e uso de AVA por alunos, foi conduzido um questionário com um grupo de 160 alunos de uma universidade privada. Os alunos são da modalidade presencial, onde $20 \%$ das disciplinas obrigatórias são oferecidas a distância com apoio de um AVA. O grupo era composto por alunos dos cursos de Tecnologia da Informação (TI) - Sistemas de Informação, Análise de Sistemas e Redes de Computadores - e Engenharias - Civil e de Produção. A coleta de dados foi realizada na última semana do semestre 2018/1 na presença do professor. Apesar da presença do professor poder ser uma ameaça à validade aos resultados do questionário, observase que a participação foi voluntária e nenhum incentivo foi oferecido. Além disto, os alunos foram informados que o objetivo do questionário era entender a motivação e aceitação deles em relação ao AVA e não os avaliar ou avaliar o professor. Deste modo, todas as respostas foram anônimas, conforme explicado no Termo de Assentimento Livre e Esclarecido. Com isso, obtivemos um total de 59 voluntários respondentes (36,8\% do total disponível), sendo 34 alunos de Tecnologia de Informação e 25 alunos de Engenharia.

A universidade que foi escopo deste estudo adota o Blackboard como AVA. Observa-se que, no momento em que a pesquisa foi realizada, os professores ainda passavam por um processo de capacitação no uso das funcionalidades do AVA e, portanto, o mesmo era utilizado basicamente para disponibilização de materiais de aula, fóruns avaliativos, vídeo aulas e avaliações online. Os professores acessavam a plataforma para tirar as dúvidas dos alunos e para corrigir os fóruns avaliativos. Todo conteúdo (materiais de aula e avaliações) era disponibilizado e gerenciado pelo núcleo de educação a distância da instituição. As avaliações eram compostas pelos seguintes instrumentos: fóruns avaliativos, prova presencial e prova online. Nem todas as disciplinas contavam com vídeo aulas, desafios ou atividades extras, deixando o aluno restrito somente ao material em formato de texto.

Os dados foram coletados através de um questionário onde os alunos informaram seus respectivos cursos e o períodos, bem como responderam 73 questões, usando uma escala Likert de sete pontos, variando de "discordo totalmente" a "concordo totalmente". Vale ressaltar que, embora o questionário tenha utilizado como base o TAM3 e a SDT, este precisou ser traduzido para a língua portuguesa adaptado ao propósito do estudo que não tinha o enfoque de tecnologia geral, mas sim específico: AVA. Por esses motivos, as questões foram traduzidas e adaptadas pelos autores, e avaliadas por dois especialistas, sendo um na área de Educação a Distância (EAD) e o outro na área de Língua Inglesa (idioma original do TAM3). O especialista em EAD ficou responsável por validar a adaptação do questionário para o contexto em questão e o especialista em Língua Inglesa ficou responsável pela validação da tradução. Em ambos os casos, foi constatado que não havia modificações a serem realizadas. As adaptações dos constructos do modelo TAM3 podem ser observadas na Tabela 1. As questões adaptadas da SDT podem ser observadas na Tabela 6.

Tabela 1: Adaptação dos constructos do Modelo TAM3

\begin{tabular}{|c|c|l|}
\hline Sigla & Constructo & \multicolumn{1}{c|}{ Definição } \\
\hline PU & Utilidade Percebida & $\begin{array}{l}\text { Grau em que um aluno acredita que usar o AVA aumentaria seu } \\
\text { desempenho nas suas atividades. }\end{array}$ \\
\hline PEOU & $\begin{array}{c}\text { Facilidade de uso } \\
\text { Percebida }\end{array}$ & $\begin{array}{l}\text { Grau em que um aluno acredita que usar o AVA estaria livre de esforço } \\
\text { físico e mental. }\end{array}$ \\
\hline SN & Norma Subjetiva & $\begin{array}{l}\text { Grau em que um aluno percebe que a maioria das pessoas que são } \\
\text { importantes para ele pensa que ele deveria ou não deveria usar o AVA. }\end{array}$ \\
\hline
\end{tabular}




\begin{tabular}{|c|c|c|}
\hline Sigla & Constructo & Definição \\
\hline VOL & Voluntariedade & $\begin{array}{l}\text { Grau em que o aluno percebe que a decisão de adoção do AVA não é } \\
\text { obrigatória. }\end{array}$ \\
\hline IMG & Imagem & $\begin{array}{l}\text { Grau em que um aluno percebe que o uso do AVA aumentará seu status } \\
\text { em seu sistema social. }\end{array}$ \\
\hline REL & $\begin{array}{l}\text { Relevância do } \\
\text { Trabalho }\end{array}$ & $\begin{array}{l}\text { Grau em que um aluno acredita que o AVA é aplicável a sua área de } \\
\text { conhecimento. }\end{array}$ \\
\hline OUT & Qualidade de Saída & Grau em que um aluno acredita que o AVA executa bem suas tarefas. \\
\hline RES & $\begin{array}{l}\text { Demonstrabilidade } \\
\text { dos Resultados }\end{array}$ & $\begin{array}{l}\text { Grau em que um aluno acredita que os resultados do uso AVA são } \\
\text { tangíveis, observáveis e comunicáveis. }\end{array}$ \\
\hline $\mathrm{BI}$ & $\begin{array}{l}\text { Intenção } \\
\text { Comportamental }\end{array}$ & Grau de intenção de usar o sistema no futuro. \\
\hline CSE & $\begin{array}{l}\text { Auto eficácia no } \\
\text { computador }\end{array}$ & $\begin{array}{l}\text { Grau em que um aluno acredita que tem a capacidade de realizar uma } \\
\text { tarefa / trabalho específico usando o AVA, sem precisar de ajuda. }\end{array}$ \\
\hline PEC & $\begin{array}{l}\text { Percepção de } \\
\text { Controle Externo }\end{array}$ & $\begin{array}{l}\text { Grau em que um aluno acredita que existem recursos educacionais e } \\
\text { técnicos para apoiar o uso do AVA. }\end{array}$ \\
\hline CPLAY & Diversão & Grau de espontaneidade cognitiva nas interações utilizando o AVA. \\
\hline CANX & $\begin{array}{l}\text { Ansiedade por } \\
\text { computador }\end{array}$ & $\begin{array}{l}\text { Grau de “apreensão" de um aluno, ou mesmo medo, quando ele se } \\
\text { depara com a possibilidade de usar o AVA. }\end{array}$ \\
\hline ENJ & Satisfação Percebida & $\begin{array}{l}\text { Até que ponto "a atividade de usar o AVA é percebida como agradável } \\
\text { por si só, além de quaisquer consequências de desempenho resultantes } \\
\text { do uso do AVA. }\end{array}$ \\
\hline
\end{tabular}

Das 73 questões, cinquenta são referentes ao modelo TAM3, sete investigam os tipos de motivação presentes na SDT e dezesseis foram desenvolvidas pelos autores com o intuito de entender do que carece o AVA a fim de que se torne mais atraente para os alunos. Estas 16 questões adicionais foram baseadas em artigos da literatura que enfatizam a importância de jogos (Koivisto, Hamari, 2019), materiais multimídias (Morais, 2018), redes sociais (Martins et al., 2013, Martins et al., 2015, Serrão et al., 2016, Teixeira et al., 2011), interação (Moore, 1989, Morais, 2018, Yacci, 2000) e ludificação (pontos extras, classificação dos resultados, recompensas, entre outras) (Koivisto e Hamari, 2019), para as grandes áreas de Sistemas de Informação (SI) e Educação. O questionário completo, com as questões associadas a cada uma destas categorias, encontra-se no Apêndice deste artigo.

\section{Resultados e Discussões}

A Tabela 2 apresenta a média geral, a mediana, a moda e o desvio padrão obtido para cada um dos constructos que compõem o modelo TAM3. Para cada um dos itens da tabela é necessário indicar o grau de concordância ou discordância para cada uma das afirmativas, de acordo com uma escala Likert de 7 pontos:

1. Discordo Totalmente

2. Discordo Moderadamente

3. Discordo um Pouco

4. Neutro 
5. Concordo um Pouco

6. Concordo Moderadamente

7. Concordo Totalmente

Para facilitar o entendimento, a média, a mediana e a moda estão acompanhadas do grau de concordância. Observa-se que a "Intenção Comportamental”, a "Auto Eficácia no Computador" e a "Ansiedade em Utilizar o Computador" apresentaram números mais elevados dentre todos os constructos analisados. Nota-se ainda que o desvio padrão apresentado para todos os constructos, mostra que houve uma dispersão nas respostas dadas pelos participantes. Tal resultado pode ser consequência de um pequeno número de participantes e de uma escala Likert com 7 pontos. O mesmo comportamento pode ser observado na Figura 2, que retrata os tipos de motivação.

Tabela 2: Análise dos resultados obtidos para os constructos que compõem o TAM3.

\begin{tabular}{|c|c|c|c|c|c|c|}
\hline Sigla & Constructo & Questões & Média & Mediana & Moda & $\begin{array}{l}\text { Desvio } \\
\text { Padrão }\end{array}$ \\
\hline PU & Utilidade Percebida & $\begin{array}{l}\text { PU1 } \\
\text { PU2 } \\
\text { PU3 } \\
\text { PU4 }\end{array}$ & $\begin{array}{l}3,758475 \\
\text { Neutro }\end{array}$ & $\begin{array}{c}4 \\
\text { Neutro }\end{array}$ & $\begin{array}{c}5 \\
\text { Concordo } \\
\text { Parcialmente }\end{array}$ & 1,711419 \\
\hline PEOU & Facilidade de uso Percebida & $\begin{array}{l}\text { PEOU1 } \\
\text { PEOU2 } \\
\text { PEOU3 } \\
\text { PEOU4 }\end{array}$ & $\begin{array}{l}\text { 3,911017 } \\
\text { Neutro }\end{array}$ & $\begin{array}{c}4 \\
\text { Neutro }\end{array}$ & $\begin{array}{c}3 \\
\text { Discordo } \\
\text { Parcialmente }\end{array}$ & 1,840149 \\
\hline $\mathrm{SN}$ & Norma Subjetiva & $\begin{array}{l}\text { SN1 } \\
\text { SN2 } \\
\text { SN3 } \\
\text { SN4 } \\
\end{array}$ & $\begin{array}{l}\text { 4,293785 } \\
\text { Neutro }\end{array}$ & $\begin{array}{c}4 \\
\text { Neutro }\end{array}$ & $\begin{array}{c}4 \\
\text { Neutro }\end{array}$ & 1,792519 \\
\hline VOL & Voluntariedade & $\begin{array}{l}\text { VOL1 } \\
\text { VOL2 } \\
\text { VOL3 }\end{array}$ & $\begin{array}{c}\text { 3,214689 } \\
\text { Discordo } \\
\text { Parcialmente }\end{array}$ & $\begin{array}{c}3 \\
\text { Discordo } \\
\text { Parcialmente }\end{array}$ & $\begin{array}{c}1 \\
\text { Discordo } \\
\text { Totalmente }\end{array}$ & 1,853142 \\
\hline IMG & Imagem & $\begin{array}{l}\text { IMG1 } \\
\text { IMG2 } \\
\text { IMG3 }\end{array}$ & $\begin{array}{c}\text { 2,847458 } \\
\text { Discordo } \\
\text { Parcialmente }\end{array}$ & $\begin{array}{c}2 \\
\text { Discordo }\end{array}$ & $\begin{array}{c}1 \\
\text { Discordo } \\
\text { Totalmente }\end{array}$ & 1,644854 \\
\hline REL & Relevância do Trabalho & $\begin{array}{l}\text { REL1 } \\
\text { REL2 } \\
\text { REL3 }\end{array}$ & $\begin{array}{l}\text { 4,231638 } \\
\text { Neutro }\end{array}$ & $\begin{array}{c}4 \\
\text { Neutro }\end{array}$ & $\begin{array}{c}6 \\
\text { Concordo }\end{array}$ & 1,882874 \\
\hline OUT & Qualidade de Saída & $\begin{array}{l}\text { OUT1 } \\
\text { OUT2 } \\
\text { OUT3 }\end{array}$ & $\begin{array}{l}3,734463 \\
\text { Neutro }\end{array}$ & $\begin{array}{c}4 \\
\text { Neutro }\end{array}$ & $\begin{array}{c}4 \\
\text { Neutro }\end{array}$ & 1,776367 \\
\hline RES & $\begin{array}{c}\text { Demonstrabilidade dos } \\
\text { Resultados }\end{array}$ & $\begin{array}{l}\text { RES1 } \\
\text { RES2 } \\
\text { RES3 } \\
\text { RES4 }\end{array}$ & $\begin{array}{c}\text { 4,508475 } \\
\text { Concordo } \\
\text { Parcialmente }\end{array}$ & $\begin{array}{c}5 \\
\text { Concordo } \\
\text { Parcialmente }\end{array}$ & $\begin{array}{c}4 \\
\text { Neutro }\end{array}$ & 1,713584 \\
\hline BI & Intenção Comportamental & $\begin{array}{l}\mathrm{BI} 1 \\
\mathrm{BI} 2 \\
\mathrm{BI} 3\end{array}$ & $\begin{array}{l}\text { 4,146893 } \\
\text { Neutro }\end{array}$ & $\begin{array}{c}4 \\
\text { Neutro }\end{array}$ & $\begin{array}{c}4 \\
\text { Neutro }\end{array}$ & 2,017131 \\
\hline CSE & Auto Eficácia no Computador & $\begin{array}{l}\text { CSE1 } \\
\text { CSE2 } \\
\text { CSE3 } \\
\text { CSE4 } \\
\end{array}$ & $\begin{array}{l}\text { 4,483051 } \\
\text { Neutro }\end{array}$ & $\begin{array}{c}5 \\
\text { Concordo }\end{array}$ & $\begin{array}{c}7 \\
\text { Concordo } \\
\text { Totalmente }\end{array}$ & 1,966814 \\
\hline PEC & $\begin{array}{l}\text { Percepção de Controle } \\
\text { Externo }\end{array}$ & $\begin{array}{l}\text { PEC1 } \\
\text { PEC2 } \\
\text { PEC3 } \\
\text { PEC4 }\end{array}$ & $\begin{array}{l}\text { 4,427966 } \\
\text { Neutro }\end{array}$ & $\begin{array}{c}4 \\
\text { Neutro }\end{array}$ & $\begin{array}{c}7 \\
\text { Concordo } \\
\text { Totalmente }\end{array}$ & 1,895328 \\
\hline
\end{tabular}




\begin{tabular}{|c|c|c|c|c|c|c|}
\hline Sigla & Constructo & Questões & Média & Mediana & Moda & $\begin{array}{l}\text { Desvio } \\
\text { Padrão }\end{array}$ \\
\hline CPLAY & Diversão & $\begin{array}{l}\text { CPLAY1 } \\
\text { CPLAY2 } \\
\text { CPLAY3 } \\
\text { CPLAY4 }\end{array}$ & $\begin{array}{c}\text { 3,300847 } \\
\text { Discordo } \\
\text { Parcialmente }\end{array}$ & $\begin{array}{c}3 \\
\text { Discordo } \\
\text { Parcialmente }\end{array}$ & $\begin{array}{c}4 \\
\text { Neutro }\end{array}$ & 1,638571 \\
\hline CANX & $\begin{array}{l}\text { Ansiedade em Utilizar o } \\
\text { Computador }\end{array}$ & $\begin{array}{l}\text { CANX1 } \\
\text { CANX2 } \\
\text { CANX3 } \\
\text { CANX4 } \\
\end{array}$ & $\begin{array}{l}\text { 3,838983 } \\
\text { Neutro }\end{array}$ & $\begin{array}{c}4 \\
\text { Neutro }\end{array}$ & $\begin{array}{c}1 \\
\text { Discordo } \\
\text { Totalmente }\end{array}$ & 2,086967 \\
\hline ENJ & Prazer Percebido & $\begin{array}{l}\text { ENJ1 } \\
\text { ENJ2 } \\
\text { ENJ3 }\end{array}$ & $\begin{array}{c}\text { 3,022599 } \\
\text { Discordo } \\
\text { Parcialmente }\end{array}$ & $\begin{array}{c}3 \\
\text { Discordo } \\
\text { Parcialmente }\end{array}$ & $\begin{array}{c}1 \\
\text { Discordo } \\
\text { Totalmente }\end{array}$ & 1,762621 \\
\hline & Média Geral & & \multicolumn{4}{|c|}{3,837167} \\
\hline
\end{tabular}

No geral, os constructos que representam o modelo TAM3 se mantiveram na neutralidade. A "demonstrabilidade dos resultados" foi o constructo que mais se aproximou da concordância, em termos de média, porém a moda mostrou que a maioria se manteve neutro. Na média, o constructo "Auto Eficácia no Computador" se manteve neutro, mas a mediana e a moda mostraram que os alunos tendem a concordar que são capazes de utilizar o AVA sem precisar de ajuda, como pode ser visto na Tabela 2. Além da "Auto Eficácia no Computador”, a maioria dos alunos concorda com os constructos "Percepção de Controle Externo", "Relevância do Trabalho" e "Utilidade Percebida". Isso significa que estão satisfeitos com os recursos educacionais e técnicos para o uso do AVA e com a aplicabilidade do AVA em seus estudos. Além disso, acreditam que a utilização do AVA melhora seu desempenho na realização de atividades.

Entretanto, a maioria dos alunos discorda quanto às questões referentes a "Facilidade de Uso Percebida”, "Voluntariedade”, "Imagem”, “Ansiedade em Utilizar o Computador” e "Prazer Percebido”. Dentro do modelo TAM3, a “Diversão” representa explicitamente a motivação intrínseca e, como pode ser visto na Tabela 2, o resultado foi baixo, o que nos leva a concluir que em geral os alunos não estão usando AVA porque querem usar, mas sim por serem obrigados a fazê-lo. Tal fato também é observado a partir da análise das questões relacionadas à SDT que foram incluídas para complementar o TAM3 (Figura 2).

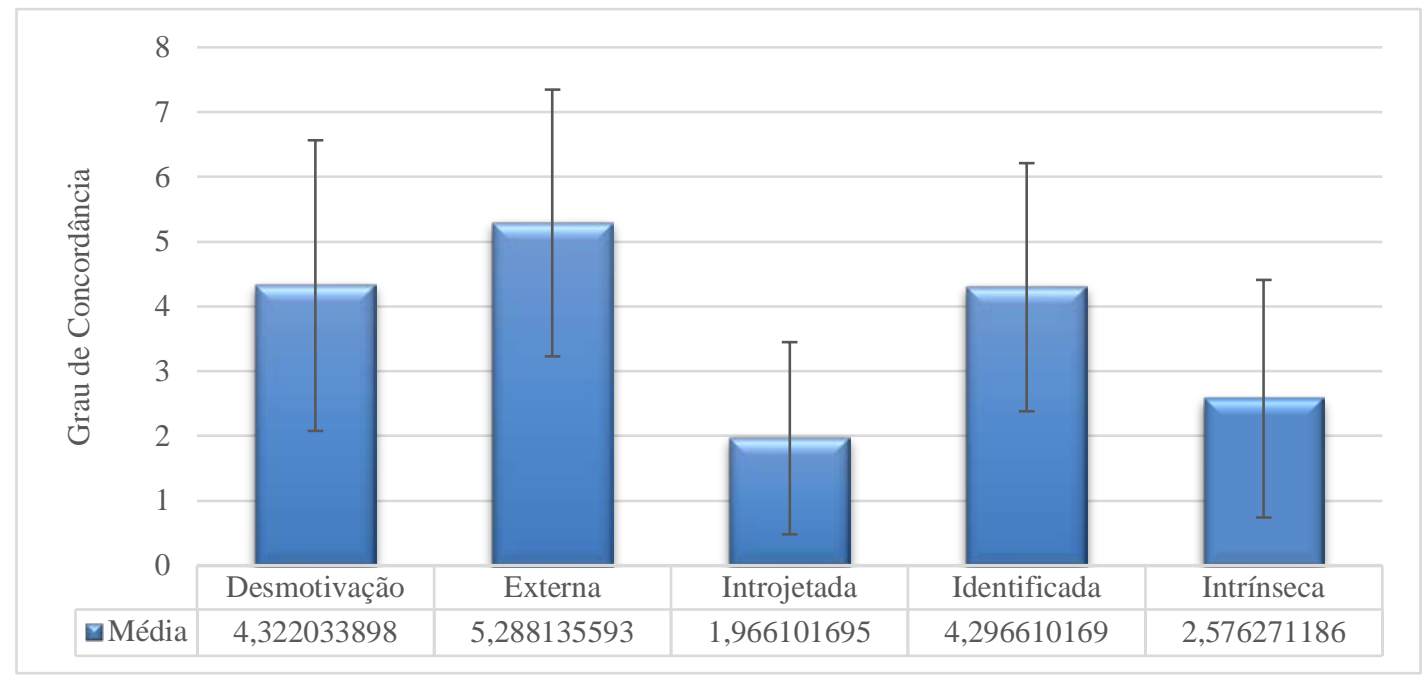

Figura 1: Representação da Motivação sob a ótica da SDT

Em média, o gráfico da Figura 2 mostra que a regulação externa teve o maior nível de concordância $(5,28)$, o que a coloca como o principal tipo de motivação para os alunos. Este é o 
tipo menos autônomo de motivação, pois se encontra mais próximo da desmotivação do que os demais tipos. Nesse caso, o indivíduo age somente em prol de recompensas ou até mesmo para evitar punições. Dentro deste contexto, acredita-se que o aluno está tentando evitar punições (perda de nota ou reprovação), pois o AVA não conta com ludificação através de sistema de recompensas. A desmotivação e a regulação identificada encontram-se praticamente no mesmo nível, se mantendo na neutralidade. A regulação identificada é aquela onde o aluno se identifica com o objetivo, percebe a importância da realização de uma determinada tarefa, ou seja, existe uma certa internalização, mesmo que o motivo para fazê-la ainda seja externo. A regulação introjetada obteve o menor resultado $(1,96)$, mas isso não é ruim, pois significa que o aluno não está utilizando o AVA mediante pressões internas como culpa, ansiedade, vergonha ou preocupações com auto aprovação, entre outras (Ryan e Connell, 1989; Ryan e Deci, 2000a).

Vale ressaltar que a regulação integrada não foi incluída neste estudo por ser muito próxima da motivação intrínseca e, ao mesmo tempo, muito difícil de ser identificada devido ao processo de internalização, bem como por estar relacionada com metas futuras. Em um estudo realizado por um dos autores da SDT, onde o objetivo era explorar as razões para uma determinada ação em dois domínios diferentes (desempenho acadêmico e comportamento pró-social), tal regulação também não foi contemplada (Ryan e Connell, 1989). Pelo fato da distinção entre os tipos de motivação não ser clara, Joo et al. (2018) também não utilizaram a regulação integrada em seu modelo que investiga as motivações e intenções dos estudantes universitários coreanos em continuar usando MOOCs (Massive Open Online Courses).

As hastes da Figura 2 representam o desvio padrão e mostram que houve uma dispersão considerável nas respostas. Por exemplo, na motivação Intrínseca as respostas variaram entre 0.74 e 4.41. Com isso, no intuito de avaliar melhor a distribuição das respostas em relação a motivação, foi utilizado um gráfico (Figura 3) do tipo boxplot (gráfico de caixa). Ele é formado pelo primeiro quartil (base da caixa), mediana, terceiro quartil (topo da caixa) e a haste que são os valores compreendidos entre a caixa e os valores limite (inferior e superior).

Através do boxplot é possível "identificar a forma da distribuição (simétrica ou assimétrica); avaliar e comparar a tendência central (mediana) de dois ou mais conjuntos de dados; e comparar a variabilidade de dois ou mais conjuntos de dados” (Reis e Reis, 2002). A distribuição pode ser observada a partir do deslocamento da caixa em relação a haste. A caixa contém $50 \%$ dos dados e o seu deslocamento na haste mostra onde estes dados estão concentrados. Se a caixa estiver no meio da haste, ou seja, se estiver dividindo-a em duas partes iguais, a distribuição é considerada simétrica. Caso a caixa esteja deslocada para um dos lados da haste, a distribuição é considerada assimétrica, pois 50\% dos dados estão concentrados daquele lado da escala (Neto et al., 2017; Reis e Reis, 2002). De acordo com Neto et al. (2017), o tamanho da caixa representa o intervalo interquartílico, ou seja, a amostra compreendida entre o primeiro quartil e terceiro quartil.

A Figura 3 mostra que, para todos os tipos de motivação houve uma assimetria na distribuição dos dados, ou seja, um deslocamento considerável para uma das extremidades da haste. Dentre todos os tipos de motivação, a regulação introjetada se destaca das demais, pois mostra uma variação somente entre o "discordo totalmente” (1) e o “discordo" (2). Ainda assim, podemos perceber a partir da mediana, representada pela linha azul que corta a caixa na horizontal, uma tendência ao “discordo totalmente”. Apesar de parecer ruim este resultado é satisfatório, pois, de acordo com a SDT, a regulação introjetada é aquela onde o indivíduo administra as consequências externas mediante o resultado de pressões internas como culpa e ansiedade (Ryan e Deci, 2000a). Neste caso específico, o aluno não está utilizando o AVA para se mostrar inteligente para os demais colegas ou para que o professor pense que ele é um bom aluno. 


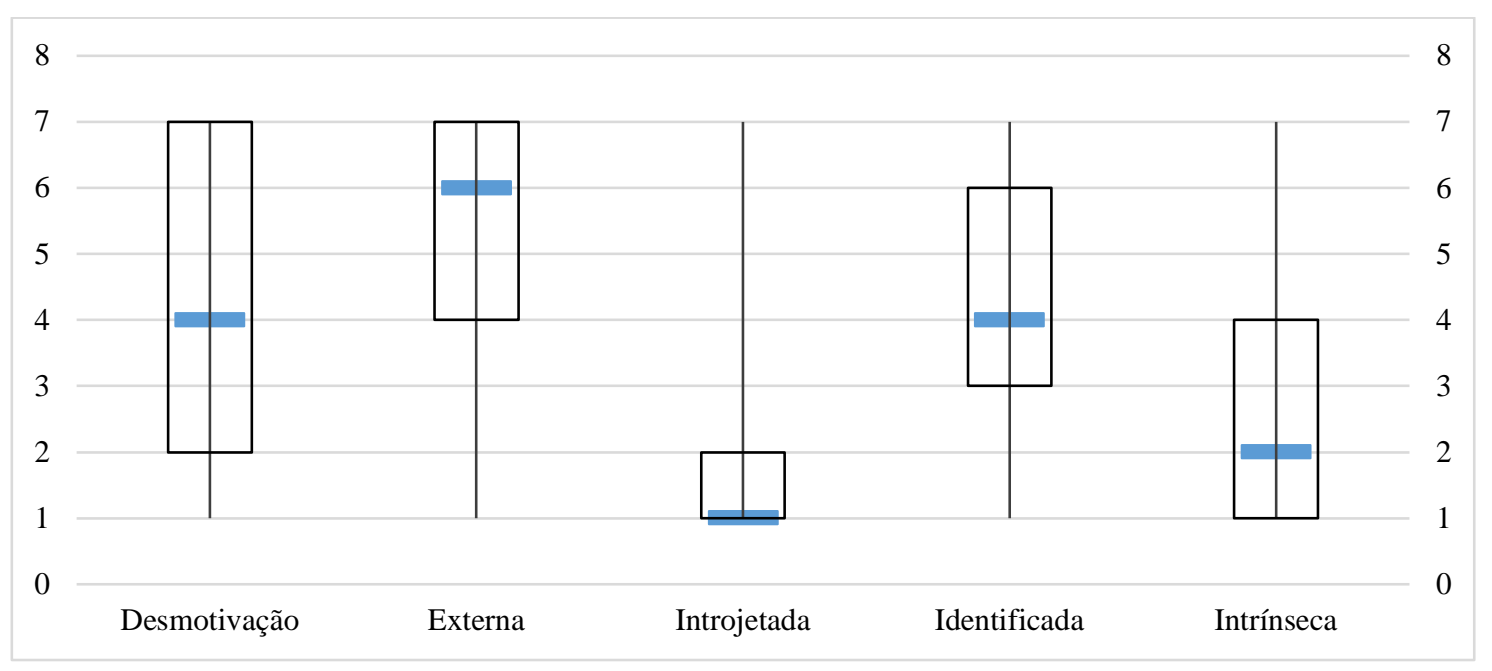

Figura 2: Distribuição das Respostas em Relação aos Tipos de Motivação

Ao contrário da regulação introjetada, a desmotivação foi a que demonstrou uma maior variação nas respostas com uma tendência à "neutralidade" (4), variando entre "discordo" e "concordo totalmente” (7). A regulação identificada também tende a ser neutra, porém variou entre "discordo parcialmente" (3) e "concordo" (6). A regulação externa variou entre a "neutralidade" e "concordo totalmente" e é a única regulação cuja tendência é concordar. Por fim, a motivação intrínseca obteve resultados opostos aos da regulação externa, pois variou entre a "neutralidade" e o “discordo totalmente”, tendendo à discordância.

Ao analisar os dados considerando o período em que cada aluno se encontra, pode-se perceber uma discrepância significativa em relação às questões da SDT. O questionário contou com alunos de diversos períodos $\left(1^{\circ}, 3^{\circ}, 4^{\circ}, 5^{\circ}, 7^{\circ}, 8^{\circ}\right.$ e $\left.10^{\circ}\right)$, que foram divididos da seguinte forma: períodos iniciais $\left(1^{\circ}\right.$ e $\left.3^{\circ}\right)$, períodos intermediários $\left(4^{\circ}\right.$ e $\left.5^{\circ}\right)$ e períodos finais $\left(7^{\circ}, 8^{\circ}\right.$ e $\left.10^{\circ}\right)$. Os alunos de períodos iniciais, concordam com a regulação identificada, indicando que consideram o AVA importante para a sua formação, mas, por outro lado, possuem um alto índice de desmotivação e regulação externa, indicando que usam o AVA por obrigação. Em comparação aos demais períodos, os alunos de períodos iniciais estão sendo um pouco menos motivados pela regulação externa e mais motivados pela regulação identificada, como pode ser visto na Figura 4.

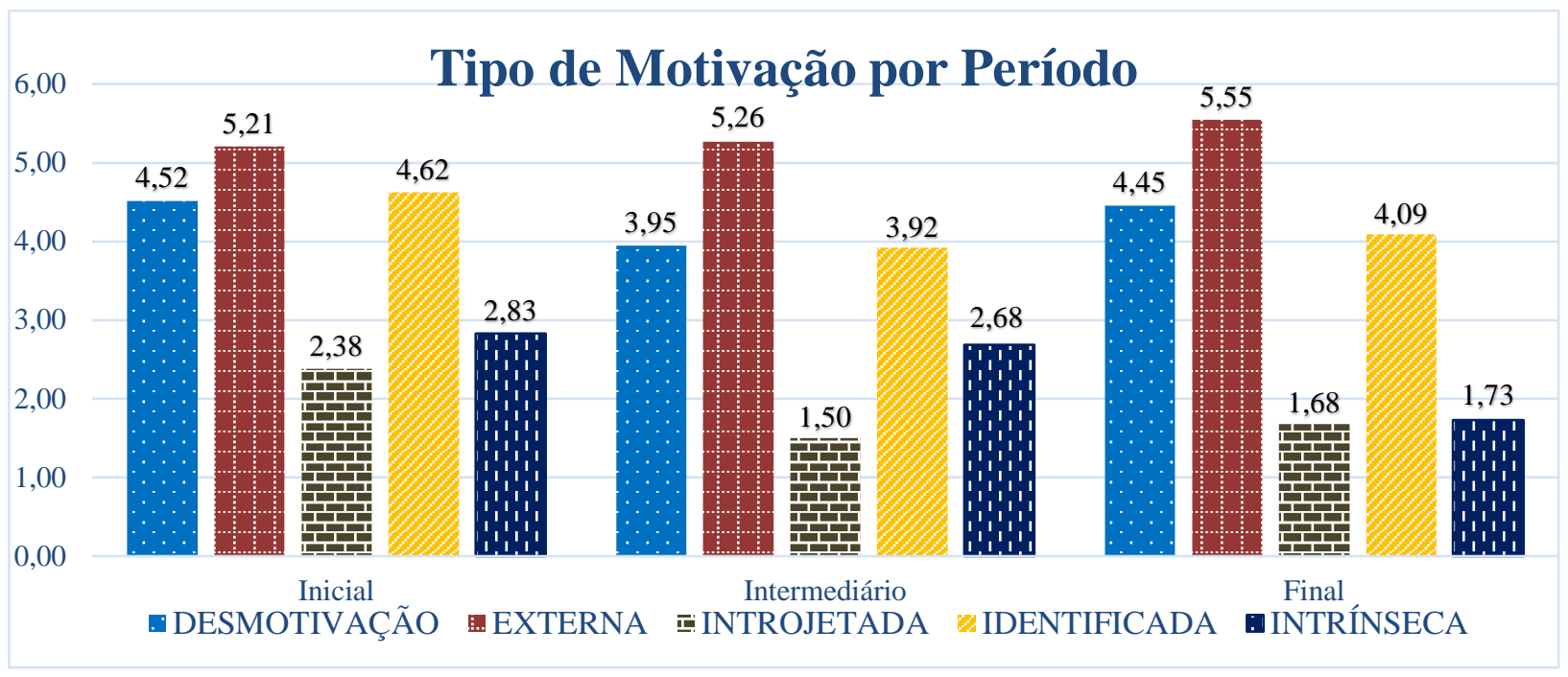

Figura 3: Análise dos Tipos de Motivação por Período 
Pode-se observar que com o passar do tempo, o processo de internalização é desfeito, pois as regulações intrínseca e identificada vão perdendo espaço para a regulação externa. Já a análise feita por curso mostrou que os resultados se mantiveram para todos os itens do questionário, não havendo discrepâncias significativas para serem aqui apresentadas. Uma possível explicação para este resultado talvez seja o fato de os cursos pertencerem a uma mesma área de conhecimento.

Em relação ao tempo médio de uso semanal do AVA, 66\% dos alunos informaram que o utilizam apenas para realizar as atividades propostas e nada mais, $17 \%$ utilizam entre 15 minutos e 1 hora e os 17\% restantes utilizam por mais de 2 horas. O tempo gasto por período não se mostrou muito diferente. Como pode ser visto na Figura 5, a maioria também só usa o AVA para o cumprimento de tarefas, ou seja, só utilizam o AVA quatro vezes por semestre. O uso entre 15 minutos e 1 hora também ficou em média de 17\%. Os alunos dos períodos intermediários não utilizam o ambiente por mais de 2 horas, enquanto 28\% dos alunos dos períodos iniciais e 18\% dos alunos dos períodos finais o utilizam por 2 horas ou mais.

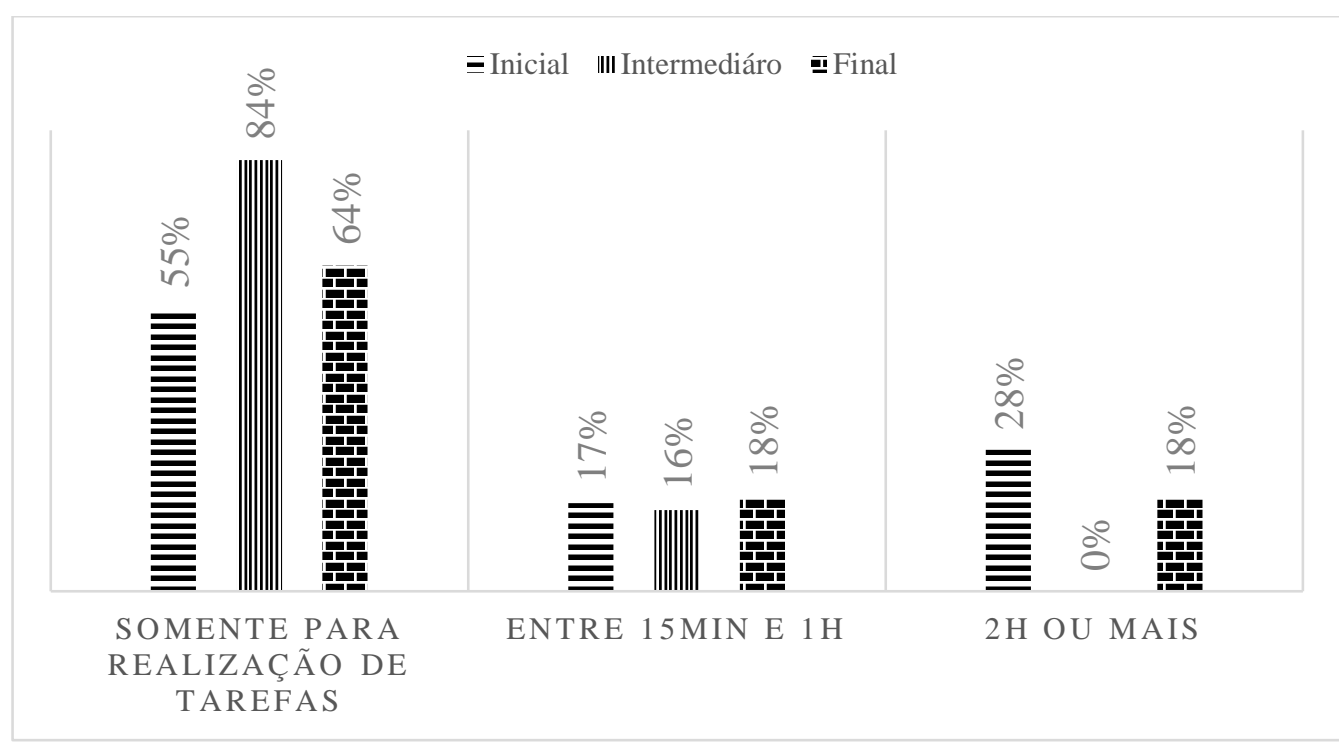

Figura 4: Tempo de Utilização do AVA por Período

Para finalizar, os alunos concordam que deveria haver maior interação com professores e tutores e inclusão de elementos de jogos para que o AVA se tornasse mais atraente. Assim como no trabalho de Mbarek e Zaddem (2013), a interação se mostrou um fator crucial para que o AVA se torne mais atrativo para os alunos. Segundo os autores, "o sentimento de interatividade dos aprendizes melhora a presença social e minimiza a sensação de isolamento". Os jogos também podem ajudar a promover a motivação nos estudantes. Silva et al. (2014) afirmam que os jogos “possuem em seu desenvolvimento elementos que garantem a existência da motivação”. Neste sentido, algumas questões tiveram um alto índice de concordância:

- $51 \%$ gostariam de desafios valendo pontos extras.

- $\quad 46 \%$ gostariam que houvesse feedback de professores ou tutores sobre o seu desempenho em cada atividade avaliativa.

- $41 \%$ gostariam que esporadicamente houvesse profissionais atuantes no mercado de trabalho participando das interações.

Vale, entretanto, ressaltar que elementos de interação, como jogos, por si só não resolverão a questão de (falta de) motivação dos alunos. O cenário é mais complexo porque há de se considerar o perfil dos alunos, as características dos recursos utilizados e o próprio contexto e ambiente de aprendizagem (Orji et al., 2014; Dos Santos et al., 2018). 
O Blackboard, AVA adotado pela Instituição, dispõe de diversos recursos (grupos, wikis, fóruns de discussão, Blackboard Collaborate ${ }^{8}$ ) capazes de promover uma maior interação entre alunos, tutores e professores. Porém, como no momento em que a pesquisa foi realizada os professores ainda passavam por um processo de capacitação, o AVA era utilizado basicamente para disponibilização de materiais de aula, fóruns avaliativos, vídeo aulas e avaliações online. Isto pode justificar um valor muito baixo para motivação intrínseca e um valor elevado para a regulação externa, uma vez que o aluno está claramente utilizando o AVA para o cumprimento de tarefas e para evitar sua reprovação.

\section{Validação de Confiabilidade}

A fim de avaliar a confiabilidade dos itens do questionário que compõem o TAM3, utilizou-se um método estatístico que, apesar das limitações indicadas na literatura (Lord e Novick, 1968; Cortina, 1993; Yang e Green, 2011), ainda é amplamente adotado para este fim: o coeficiente alfa de Cronbach. Desenvolvido em 1951 por Lee J. Cronbach e amplamente citado na literatura, o alfa de Cronbach tem por objetivo medir "a correlação esperada de dois testes que medem o mesmo constructo” (Xexéo, 2009; Cronbach, 1951; Freitas e Rodrigues, 2005).

O resultado obtido é um fator que indica do grau de confiabilidade das respostas do questionário, porém, não existe um consenso entre os pesquisadores em relação à interpretação da confiabilidade obtida a partir do valor deste coeficiente. De acordo com Freitas e Rodrigues (2005) os valores entre 0,60 e 0,70 são considerados aceitáveis em pesquisas exploratórias. George e Mallery (2012) definem a seguinte regra para o alfa de Cronbach: $\alpha>0,90$ : excelente; $\alpha>0,80$ : bom; $\alpha>0,70$ : aceitável; $\alpha>0,60$ : questionável; $\alpha>0$,5: pobre; e $\alpha<=0,5$ : inaceitável. A Tabela 3 mostra o resultado do alfa de Cronbach aplicado nos constructos do modelo TAM3.

Tabela 3: Alfa de Cronbach do Modelo TAM3

\begin{tabular}{|l|c|}
\hline \multicolumn{1}{|c|}{ Constructo } & Alfa de Cronbach \\
\hline Utilidade Percebida (PU) & 0,929 \\
\hline Facilidade de Uso Percebida (PEOU) & 0,763 \\
\hline Norma Subjetiva (SN) & $\mathbf{0 , 3 4 7} *$ \\
\hline Voluntariedade (VOL) & $\mathbf{0 , 4 3 1}$ \\
\hline Imagem (IMG) & 0,769 \\
\hline Relevância do Trabalho (REL) & $\mathbf{0 , 5 4 4}$ \\
\hline Qualidade de Saída (OUT) & 0,766 \\
\hline Demonstrabilidade dos Resultados (RES) & $\mathbf{0 , 4 4 5}$ \\
\hline Intenção Comportamental (BI) & 0,903 \\
\hline Auto Eficácia no Computador (CSE) & 0,669 \\
\hline Percepção de Controle Externo (PEC) & $\mathbf{0 , 3 7 9}$ \\
\hline Diversão (CPLAY) & 0,817 \\
\hline Ansiedade em Utilizar o Computador (CANX) & $\mathbf{0 , 2 1 9}$ \\
\hline Satisfação Percebida (ENJ) & 0,683 \\
\hline
\end{tabular}

\footnotetext{
${ }^{8}$ Ferramenta de videoconferência que permite o compartilhamento de arquivos.
} 


\begin{abstract}
* O valor do constructo "Norma Subjetiva” foi desconsiderada deste estudo, pois no questionário submetido para os alunos faltou a questão SN3, o que implica diretamente no coeficiente alfa abaixo de 0,6.
\end{abstract}

Os constructos "Utilidade Percebida” (PU), "Intenção Comportamental” (BI) e "Diversão" (CPLAY) apresentaram os melhores resultados. Em contrapartida, "Voluntariedade" (VOL), "Relevância do Trabalho" (REL), "Demonstrabilidade dos Resultados” (RES), "Percepção de Controle Externo" (PEC) e “Ansiedade em Utilizar o Computador” (CANX), tiveram um resultado inaceitável ou insatisfatório. Isso pode ser reflexo do número pequeno de participantes e de uma grande variabilidade nas respostas. Segundo Cronbach e Shavelson (2004, p.25 apud Costa, 2013, p. 21), fatores como, questionário com um número excessivo de itens, tempo de aplicação do questionário e uma amostra muito homogênea, podem influenciar na consistência interna dos itens do questionário.

Uma técnica que pode ser utilizada para reduzir o problema de baixa correlação entre os itens de um constructo é a "Purificação da Escala" (Parasuraman et al., 1988), ou seja, a eliminação de um ou mais itens do constructo com o objetivo de analisar o comportamento do coeficiente alfa e, assim, estipular quais itens estão prejudicando a confiabilidade do questionário. Se o coeficiente alfa aumentar, o item removido não é altamente correlacionado com os demais itens do constructo. Caso contrário (diminuição do valor de alfa), o item removido é altamente relacionado com os outros itens do constructo em questão e não deve ser removido. Como pode ser visto na Tabela 4, todos os constructos que apresentaram coeficiente menor que 0,6 tiveram o seu alfa elevado após a remoção de um único item.

Tabela 4: Purificação da Escala dos constructos que obtiveram alfa abaixo de 0,6.

\begin{tabular}{c|c|c|c|c|c|c|c}
\hline Constructo & $\begin{array}{c}\text { Alfa } \\
\text { Inicial }\end{array}$ & $\begin{array}{c}\text { Total } \\
\text { de Itens }\end{array}$ & $\begin{array}{c}\text { Total de } \\
\text { Removidos }\end{array}$ & $\begin{array}{c}\text { Remoção } \\
\mathbf{( \% )}\end{array}$ & $\begin{array}{c}\text { Item } \\
\text { Removido }\end{array}$ & $\begin{array}{c}\text { Alfa } \\
\text { Purificado }\end{array}$ & $\begin{array}{c}\text { Incremento } \\
\text { (\%) }\end{array}$ \\
\hline VOL & 0,431 & 3 & 1 & 33,33 & VOL1 & $\mathbf{0 , 4 6 2}$ & 10,44 \\
REL & 0,544 & 3 & 1 & 33,33 & REL2 & 0,629 & 15,63 \\
RES & 0,445 & 4 & 1 & 25,00 & RES4 & 0,738 & 65,84 \\
PEC & 0,379 & 4 & 1 & 25,00 & PEC4 & 0,707 & 86,54 \\
CANX & 0,219 & 4 & 1 & 25,00 & CANX1 & 0,702 & 220,55 \\
\hline
\end{tabular}

O constructo “Ansiedade em Utilizar o Computador” (CANX) se destaca dos demais, pois o seu coeficiente passou de 0,219 para 0,702, ou seja, sofreu um incremento de $2220,55 \%$ na confiabilidade após a purificação, o maior incremento dentre todos os constructos analisados. Já o constructo "Demonstrabilidade dos Resultados" (RES) obteve o maior valor de alfa purificado dentre os cinco. A "Voluntariedade" (VOL) foi o único constructo que não conseguiu alcançar alfa $>=0,6$, além disso, foi o único que teve o menor incremento na confiabilidade após a purificação. Apesar do seu resultado demonstrar uma consistência abaixo do esperado, ainda é prematuro dizer que os itens dos constructos VOL possuem baixa correlação entre si no contexto de avaliação de uso e aceitação de um AVA.

Além disso, outros constructos também apresentaram um alfa elevado após a purificação dos resultados, mesmo apresentando inicialmente, $\alpha>0,6$ (Tabela 5).

Tabela 5: Purificação da Escala dos constructos que obtiveram alfa acima de 0,6.

\begin{tabular}{c|c|c|c|c|c|c|c}
\hline Constructo & $\begin{array}{c}\text { Alfa } \\
\text { Inicial }\end{array}$ & $\begin{array}{c}\text { Total } \\
\text { de Itens }\end{array}$ & $\begin{array}{c}\text { Total de } \\
\text { Removidos }\end{array}$ & $\begin{array}{c}\text { Remoção } \\
\mathbf{( \% )}\end{array}$ & $\begin{array}{c}\text { Item } \\
\text { Removido }\end{array}$ & $\begin{array}{c}\text { Alfa } \\
\text { Purificado }\end{array}$ & $\begin{array}{c}\text { Incremento } \\
\text { (\%) }\end{array}$ \\
\hline PU & 0,929 & 4 & 1 & 25,00 & PU4 & 0,958 & 3,12 \\
PEOU & 0,763 & 4 & 1 & 25,00 & PEOU2 & 0,768 & 0,66 \\
IMG & 0,769 & 3 & 1 & 33,33 & IMG3 & 0,775 & 0,78
\end{tabular}




\begin{tabular}{c|c|c|c|c|c|c|c}
\hline Constructo & $\begin{array}{c}\text { Alfa } \\
\text { Inicial }\end{array}$ & $\begin{array}{c}\text { Total } \\
\text { de Itens }\end{array}$ & $\begin{array}{c}\text { Total de } \\
\text { Removidos }\end{array}$ & $\begin{array}{c}\text { Remoção } \\
\mathbf{( \% )}\end{array}$ & $\begin{array}{c}\text { Item } \\
\text { Removido }\end{array}$ & $\begin{array}{c}\text { Alfa } \\
\text { Purificado }\end{array}$ & $\begin{array}{c}\text { Incremento } \\
\text { (\%) }\end{array}$ \\
\hline OUT & 0,766 & 3 & 1 & 33,33 & OUT1 & 0,802 & 4,70 \\
CSE & 0,669 & 4 & 1 & 25,00 & CSE1 & 0,712 & 6,43 \\
CPLAY & 0,817 & 4 & 1 & 25,00 & CPLAY4 & 0,865 & 5,88 \\
ENJ & 0,683 & 3 & 1 & 33,33 & ENJ3 & 0,825 & 20,79 \\
\hline
\end{tabular}

Além de obter o maior valor de alfa, a "Utilidade Percebida” pode ter o seu coeficiente ainda mais alto com a remoção do item PU4. Assim como valores abaixo de seis não são bem vistos, valores acima de nove também não são. De acordo com Taber (2018), não deve-se presumir que um valor elevado de alfa seja bom, pois em alguns casos, "um valor muito alto pode indicar um nível ineficiente de redundância nos itens”.

De acordo com Pasquali (2003 apud Maroco e Garcia-Marques, 2013, p. 2), dentro do conceito de fiabilidade, o "erro é a variabilidade observada no processo de mensuração de um mesmo objeto. Ausência de erro é consistência”. Este estudo contou com uma amostra relativamente pequena de respondentes durante a aplicação do questionário. Além disso, eles apresentam perfil bastante homogêneo, ou seja, todos são estudantes de cursos pertencentes a uma mesma área de conhecimento. Acredita-se que tais fatores possam ter influenciado diretamente no resultado da confiabilidade do TAM3.

\section{Limitações do Trabalho e Ameaças ao Método}

Em relação à revisão sistemática, podem ser observadas algumas limitações do trabalho e ameaças ao método, como a restrição das bases utilizadas e as palavras-chave utilizadas nas consultas. Para minimizar os potenciais impactos destas ameaças, um conjunto de trabalhos de referência sobre o tema foram previamente selecionados e utilizados para verificação e análise dos resultados das buscas. Observa-se ainda que o fato de utilizar o Google Scholar como uma das bases de pesquisa possibilitou capturar uma ampla gama de trabalhos, inclusive que utilizassem termos levemente diferentes (como por exemplo diferentes grafias de self-determination theory).

As delimitações em relação ao idioma (apenas trabalhos em inglês) e tamanho dos trabalhos (cinco ou mais páginas) se justificam pelo fato de ser o idioma oficialmente adotado internacionalmente para publicações científicas, bem como pela complexidade da combinação de modelos de aceitação de tecnologia com a teoria de autodeterminação, que implicariam em trabalhos mais extensos.

Ainda em relação à revisão sistemática, a verificação de atendimento da questão de pesquisa ( $2^{a}$ etapa da RSL) e verificação se os trabalhos contemplavam a combinação da SDT com o TAM ( $3^{\text {a }}$ etapa da RSL) foi realizada por apenas um pesquisador. Para lidar com esta ameaça, as justificativas de exclusão foram registradas detalhadamente pelo pesquisador e foram verificadas e aprovadas por um pesquisador adicional.

Em relação à aplicação do questionário, a pequena quantidade de respondentes e também a homogeneidade de seus perfis (todos pertencem a cursos de uma mesma área de conhecimento) podem ter influenciado no resultado desta pesquisa. Tal restrição deve-se ao fato de embora diversas instituições terem sido contatadas para possível participação no estudo, apenas tivemos aprovação de uma instituição e em um escopo reduzido de alunos até o momento deste artigo. Entretanto, espera-se que com o trabalho realizado, seja mais fácil demonstrar a relevância do estudo e com isto um escopo mais amplo e heterogêneo para futuros estudos. 
Os participantes assinaram o Termo de Assentimento Livre e Esclarecido para poderem ser contabilizados na pesquisa, embora tivessem livre acesso ao questionário e liberdade para parar de responder a qualquer momento. Observa-se ainda que a participação foi voluntária e nenhum incentivo foi oferecido, bem como foi explicitado que os alunos e os professores não estavam sendo avaliados através do questionário e o fato de responderem ou não ao questionário não implicaria em nenhum benefício ou penalidade. Deste modo, apesar do professor permanecer em sala durante a aplicação do questionário, embora possa ser uma ameaça à validade do mesmo, considera-se que estes fatores tenham contribuído para não representar algo significativo.

O fato de considerarmos uma escala Likert de sete pontos pode ter contribuído para a dispersão das respostas e, portanto, também configura uma ameaça à validade dos resultados. Entretanto, isto é justificável devido ao fato de tradicionalmente em estudos com o TAM ter sido esta a escala adotada.

Finalmente, o uso do coeficiente alfa de Cronbach pode representar uma ameaça à validade da pesquisa devido às limitações indicadas na literatura. Entretanto, seu uso de justifica devido a facilidade em seu uso e ao fato ainda de ser amplamente utilizado.

\section{Conclusão}

De acordo com o CensoEAD.BR 2017/2018 ${ }^{9}$, nos últimos anos verificou-se um crescimento exponencial da EAD (Educação a Distância) atuando não somente nos cursos totalmente a distância, mas também servindo como suporte para os cursos presenciais de nível superior. Para isto, observa-se um conjunto de ferramentas que permite o acesso a um curso ou disciplina a distância e também promove a interação entre alunos, professores e tutores envolvidos no processo de ensino-aprendizagem.

O presente trabalho explorou os fatores e os tipos de motivação que influenciam o uso e a aceitação de um AVA em uma universidade privada. Foi desenvolvido e aplicado um questionário para os alunos, que consiste em de uma extensão do questionário do modelo TAM3 com conceitos da SDT, de ludificação e outros. A análise dos resultados mostra que tal combinação foi bastante eficaz, pois foi possível identificar o tipo de motivação que leva o aluno a utilizar o AVA e comprovar o baixo índice da motivação intrínseca descrita pelo TAM3 como "Diversão". O questionário revelou que os constructos "Demonstrabilidade dos Resultados”, "Auto Eficácia no Computador" e "Percepção de Controle Externo" do TAM3 são os que possuem maior influência no uso e aceitação do AVA.

Em relação à motivação, os resultados revelam que os alunos se encontram desmotivados e só utilizam o AVA para realizar tarefas. Os resultados mostraram também que no início da graduação, os alunos utilizam o AVA porque o consideram importante para sua formação e, ao longo dos anos, o processo de internalização é desfeito e as regulações identificada e intrínseca vão perdendo espaço para a regulação externa, indicando que o indivíduo está agindo somente em prol de recompensas ou até mesmo para evitar punições e não por prazer ou vontade própria.

Através da combinação do TAM3 com a SDT foi possível identificar e comprovar o tipo de motivação que está levando o aluno a utilizar o AVA, o processo de internalização subjacente ao uso e os principais constructos do modelo TAM3 que estão influenciando diretamente no uso e aceitação do AVA. Sem isso, só seria possível analisar através de uma única perspectiva: motivação ou uso e aceitação. Além disso, os itens do questionário elaborados para auxiliar no

${ }^{9}$ http://abed.org.br/arquivos/CENSO_EAD_BR_2018_impresso.pdf 
entendimento das características que faltam ao AVA para torná-lo mais atrativo mostraram que faltam incentivo e recompensas por parte da Instituição, ou seja, mais elementos para motivação extrínseca. Este resultado concorda com as crenças dos autores do modelo TAM3. Segundo eles, “o incentivo é uma importante recompensa extrínseca que pode reduzir a ansiedade e aumentar o prazer percebido, uma vez que as recompensas são consideradas importantes impulsionadores de motivações intrínsecas” (Venkatesh e Bala 2008).

Para medir a consistência interna entre os itens do questionário que compõem o modelo TAM3, foi utilizado método de validação de confiabilidade muito utilizado na literatura, o coeficiente alfa de Cronbach. De acordo com Hayes (2001), "quanto maior for a inter-relação entre os itens, maior será a confiabilidade de toda a escala”. Os resultados foram bastante satisfatórios neste cenário, pois mais da metade dos constructos se mostraram aceitáveis, segundo a classificação de alguns autores. Após a técnica de "Purificação de Escala”, os constructos que obtiveram valores abaixo de 0,6 tiveram o seu alfa aumentado. Os constructos "Demonstrabilidade dos Resultados" (RES), "Percepção de Controle Externo" (PEC) e “Ansiedade em Utilizar o Computador" (CANX) sofreram um incremento acima de 50\% na confiabilidade. O constructo que representa a voluntariedade (VOL) foi o único que não conseguiu alcançar o valor de alfa $>=0,6$, além disso, foi o único que teve o menor incremento $(\sim 10,44 \%)$ na confiabilidade após a purificação. Vale ressaltar que, dentre os constructos que apresentaram os melhores resultados está a "Diversão" (0,865 - após a purificação da escala), constructo do modelo TAM3 que representa a motivação, indicando que houve uma correlação significativa entre os itens que formam este constructo. Além disso, a técnica de purificação de escala mostrou que 11 questões podem ser removidas do questionário sem comprometer a consistência interna dos constructos que compõem o modelo TAM3.

Como trabalhos futuros espera-se avaliar o questionário, mantendo-se todos os itens dos constructos, com uma quantidade maior de respondentes e também uma maior heterogeneidade em relação a seus perfis (alunos de outras áreas de conhecimento e de outras instituições). Com isso, será possível concluir de fato a correlação entre os itens que compõem o Modelo TAM3 quando utilizado para analisar a aceitação e uso de um Ambiente Virtual de Aprendizagem. Além disso, será possível também reduzir o número de questões, baseado na purificação da escala, sintetizando o questionário a fim de obter uma maior efetividade na sua aplicação.

Serão investigados também a modalidade totalmente a distância e o uso do AVA como ferramenta de apoio para a modalidade presencial. Além disso, seria interessante considerar uma análise da motivação, da aceitação e do uso de diferentes AVAs.

\section{Referências}

Abdallah, N. A. O., Ahlan, A. R., \& Abdullah, O. A. (2016). Factors Affecting Instructors' Adoption of Learning Management Systems: A Theoretical Framework. In 6th International Conference on Information and Communication Technology for The Muslim World, 13-18. doi:10.1109/ICT4M.2016.15 [GS Search]

Abdullah, F., \& Ward, R. (2016). Developing a General Extended Technology Acceptance Model for E-Learning (GETAMEL) by analysing commonly used external factors. Computers in Human Behavior, 56, 238-256. doi: 10.1016/j.chb.2015.11.036 [GS Search]

Ajzen, I. (1991). The Theory of Planned Behavior. Organizational Behavior and Human Decision Processes, 50(2), 179-211. doi: 10.1016/0749-5978(91)90020-T [GS Search]

Akhlaq, A., \& Ahmed, E. (2013). The effect of motivation on trust in the acceptance of internet 
banking in a low income country. International Journal of Bank Marketing, 31(2), 115-125. doi: $\underline{10.1108 / 02652321311298690}$ [GS Search]

Al-sayyed, F. S. (2015). A Framework for e-Learning Acceptance: A Case Study of the Palestinian Universities. Faculty of Graduate Studies. Retrieved from https://www.mobt3ath.com/uplode/book/book-4319.pdf [GS Search]

Appel-Silva, M.; Wendt, G.; \& Argimon, I. (2011). A Teoria da Autodeterminação e as Influências Sócio-culturais Sobre a identidade. Psicologia Em Revista, 16(2), 351-369. doi: 10.5752/P.1678-9563.2010v16n2p351 [GS Search]

Balog, A. (2015). Acceptance of e-Learning Systems : a Serial Multiple Mediation Analysis. Studies in Informatics and Control, 24(1), 101-110. [GS Search]

Chen, K., \& Jang, S. (2010). Motivation in online learning: Testing a model of self-determination theory. Computers in Human Behavior, 26(4), 741-752. doi: 10.1016/j.chb.2010.01.011 [GS Search]

Cheng, X., Zhu, R., \& Fu, S. (2016). Modeling the Motivation of Users' Sharing Option: A Case Study Based on A Car-Sharing Digital Platform. Fifteenth Wuhan International Conference on E-Business, 45-52. Retrieved from http://aisel.aisnet.org/whiceb2016/64 [GS Search]

Cortina, J. (1993). What is coefficient alpha? An examination of theory and applications. Journal of Applied Psychology. 78(1), 98-104. doi: 10.1037/0021-9010.78.1.98 [GS Search]

Costa, J. A. da. (2013). O índice Alfa de Cronbach como Ferramenta na Avaliação do Instrumento de Pesquisa Aplicado na Prática de Gestão por Competências. UFRRJ. Retrieved from http://cursos.ufrrj.br/grad/matematica/files/2016/09/615_joiceamaral.pdf

Cronbach, L. J. (1951). Coefficient alpha and the internal structure of tests. Psychometrika, 16(3), 297-334. doi: 10.1007/BF02310555 [GS Search]

Cronbach, L. J., \& Shavelson, R. J. (2004). My Current Thoughts on Coefficient Alpha and Successor Procedures. Educational and Psychological Measurement, 64(3), 391-418. doi: 10.1177/0013164404266386 [GS Search]

Davis, F. D. (1989). Perceived Usefulness, Perceived Ease of Use, and User Acceptance of Information Technology. MIS Quarterly, 13(3), 319. doi: 10.2307/249008 [GS Search]

De Oliveira, N. J. S., Siqueira, S.W. M., \& De Andrade, L. C. V. (2018). OntoMotivation: Combining Motivation Theories. In 2018 XLIV Latin American Computer Conference (CLEI). IEEE, p. 344-352. doi: 10.1109/CLEI.2018.00049 [GS Search]

Deci, E. L., \& Ryan, R. M. (1985). Intrinsic Motivation and Self-Determination in Human Behavior. New York: Plenum Press. [GS Search]

Delone, W., \& Mclean, E. (2003). The DeLone and McLean Model of Information Systems Success: A Ten-Year Update. Journal of Management Information Systems, 19(4), 9-30. doi: $\underline{10.1080 / 07421222.2003 .11045748}$ [GS Search]

Deterding, S., \& Dixon, D. (2011). From Game Design Elements to Gamefulness : Defining "Gamification." In Proceedings of the 15th international academic MindTrek conference: Envisioning future media environments. ACM 9-15. doi: $\underline{10.1145 / 2181037.2181040}$ [GS Search]

Dos Santos, W. O., \& Isotani, S. (2018). Desenvolvimento de Jogos Educativos? Desafios, Oportunidades e Direcionamentos de Pesquisa. RENOTE. 16(2), 180-189. doi: $\underline{10.22456 / 1679-1916.89252}$ [GS Search] 
Dupuy, L., Consel, C., \& Sauzéon, H. (2016). Self determination-based design to achieve acceptance of assisted living technologies for older adults l e, 65, 508-521. doi: 10.1016/j.chb.2016.07.042 [GS Search]

Fishbein, M., \& Ajzen, I. (1975). Belief, attitude, intention, and behavior: An introduction to theory and research. Reading, MA: Addison-Wesley. [GS Search]

Freitas, A. L. P., \& Rodrigues, S. G. (2005). A avaliação da confiabilidade de questionários: uma análise utilizando o coeficiente alfa de Cronbach. In XII SIMPEP (pp. 1-15). [GS Search]

George, D., \& Mallery, M. (2012). IBM SPSS Statistics 19 step by step: a simple guide and reference (12th ed.). Boston: Pearson. [GS Search]

Gerow, J. E. et al. (2013). Can we have fun@work? The role of intrinsic motivation for utilitarian systems. European Journal of Information Systems, 22(3), 360-380. doi: 10.1057/ejis.2012.25 [GS Search]

Guimarães, S. É. R., \& Bzuneck, J. A. (2008). Propriedades psicométricas de um instrumento para avaliação da motivação de universitários. Ciências \& Cognição, 13(1), 101-113. Retrieved from http://cienciasecognicao.org/revista/index.php/cec/article/view/682 [GS Search]

Hamari, J., \& Keronen, L. (2017). Why do people play games? A meta-analysis. International Journal of Information Management, 37(3), 125-141. doi: 10.1016/j.ijinfomgt.2017.01.006 [GS Search]

Hayes, B. E. (2001). Medindo a Satisfação do Cliente. Desenvolvimento e Uso de Questionários. Qualitymark (1th). [GS Search]

Herzberg, F. I. (1968). One more time: how do you motivate employees? Harvard Business Review, 46(1), 53-62. [GS Search]

Hew, T., Latifah, S., \& Abdul, S. (2016). Understanding cloud-based VLE from the SDT and CET perspectives: Development and validation of a measurement instrument. Computers \& Education, 101, 132-149. doi: 10.1016/j.compedu.2016.06.004 [GS Search]

Howard, N. L., Marshall, P., \& Swatman, P. A. (2010). Reconceptualising Motivation in Adoption and Acceptance Research: Back to Basics to Basics. In 21st Australasian Conference on Information Systems. ACIS 2010 Proceedings. Retrieved from http://aisel.aisnet.org/acis2010/99 [GS Search]

Hsu, Y.-C., Shiue, Y.-M., \& Sheng, M.-H. (2016). Continuous intention formation in E-tutoring system: Examining the roles of self-determined motivators, social and technological influences. In Proceedings of the IEEE International Conference on Advanced Materials for Science and Engineering IEEE-ICAMSE. doi: 10.1109/ICAMSE.2016.7840276 [GS Search]

Huang, H. et al. (2018). Impact of online gamers' personality traits on interdependence, network convergence, and continuance intention : Perspective of social exchange theory. International Journal of Information Management, 38(1), 232-242. doi: 10.1016/j.ijinfomgt.2017.08.009 [GS Search]

Joo, Y. J., So, H., \& Kim, N. H. (2018). Examination of relationships among students 'selfdetermination, technology acceptance, satisfaction, and continuance intention to use KMOOCs. Computers \& Education, 122(April 2017), 260-272. doi: 10.1016/j.compedu.2018.01.003 [GS Search]

Kang, Y. J., Lee, J. Y., \& Kim, H.-W. (2017). A psychological empowerment approach to online knowledge sharing. Computers in Human Behavior, 74, 175-187. doi: 10.1016/j.chb.2017.04.039 [GS Search] 
Kalus, G., \& Kuhrmann, M. (2013). Criteria for Software Process Tailoring: A Systematic Review. In Proceedings of the 2013 International Conference on Software and System Process. ACM, 171-180. doi: 10.1145/2486046.2486078 [GS Search]

Kirschner, P. A., \& Neelen, M. (2016). Close The Stable Doors: Effects of Motivation and Engagement on Learner Achievement? Retrieved from https://3starlearningexperiences.wordpress.com/2016/05/17/close-the-stable-doors-effectsof-motivation-anengagement-on-learner-achievement/

Kitchenham, B. \& Charters, S. (2007). Guidelines for performing Systematic Literature Reviews in Software Engineering (Vol. 2). EBSE Technical Report EBSE-2007-01. Retrieved from https://www.elsevier.com/_data/promis_misc/525444systematicreviewsguide.pdf [GS Search]

Koivisto, J., \& Hamari, J. (2019). The rise of motivational information systems: A review of gamification research. International Journal of Information Management, 45, 191-210. doi: 10.1016/j.ijinfomgt.2018.10.013 [GS Search]

Lee, S. K., \& Yu, J. H. (2013). Effects of intrinsic and extrinsic motivation factors on BIM acceptance. Journal of the Korea Institute of Building Construction, 13(3), 242-252. doi: 10.5345/JKIBC.2013.13.3.242 [GS Search]

Lee, Y., Lee, J., \& Hwang, Y. (2015). Relating motivation to information and communication technology acceptance: Self-determination theory perspective. Computers in Human Behavior, 51, 418-428. doi: 10.1016/j.chb.2015.05.021 [GS Search]

Lin, S., Persada, S. F., \& Nadlifatin, R. (2014). A Study of Student Behavior in Accepting the Blackboard Learning System : a Technology Acceptance Model (TAM) Approach. In IEEE 18th International Conference on Computer Supported Cooperative Work in Design (pp. 457-462). doi: 10.1109/CSCWD.2014.6846888 [GS Search]

Lopes, R. A., Toda, A. M., \& Brancher, J. D. (2015). Um estudo preliminar sobre elementos extrínsecos e intrínsecos do processo de Gamification. Revista Brasileira de Informática Na Educação (RBIE), 23(3), 164-173. doi: 10.5753/rbie.2015.23.03.164 [GS Search]

Lord, F. M., \& Novick, M. R. (1968). Statistical Theories of Mental Test Scores. Menlo Park, CA: Addison-Wesley Publishing Company. [GS Search]

MacGregor, D. (1960). No Title. In The human side of enterprise. McGraw-Hill: New York. [GS Search]

Maroco, J., \& Garcia-Marques, T. (2013). Qual a fiabilidade do alfa de Cronbach? Questões antigas e soluções modernas? Laboratório de Psicologia, 4(1), 65-90. doi: 10.14417/lp.763 [GS Search]

Martins, B. S. B., Neto, J. C. S. DE O., \& Aquino, F. J. A. De. (2013). O Uso de Redes Sociais na EAD: Integração Do Facebook no Ava Solar 2.0. In XLI Congresso Brasileiro de Educação em Engenharia - CONBENGE. Gramado, RS. Retrieved from https://www.fadep.br/engenharia-eletrica/congresso/pdf/117902_1.pdf

Martins, J. et al. (2015). Proposta de um Modelo de e-Learning Social. Revista Ibérica de Sistemas e Tecnologias de Informação, 16(2), 92-108. doi: 10.17013/risti.16.92-107 [GS Search]

Maslow, A. H. (1943). A theory of human motivation. Psychological Review, 50(4), 370. doi: https://psycnet.apa.org/doi/10.1037/h0054346 [GS Search]

Mbarek, R., \& Zaddem, F. (2013). The examination of factors affecting e-learning effectiveness. International Journal of Innovation and Applied Studies, 2(4), 423-435. [GS Search] 
Mclean, G. (2018). Examining the determinants and outcomes of mobile app engagement - A longitudinal perspective. Computers in Human Behavior, 84, 392-403. doi: 10.1016/j.chb.2018.03.015 [GS Search]

Moore, M. G. (1989). Editorial: Three types of interaction. The American Journal of Distance Education, 3(2), 1-7. doi: 10.1080/08923648909526659 [GS Search]

Morais, A. M. De. (2018). Abordagem Avaliativa Multidimensional para Previsão da Evasão do Discente em Cursos Online. Tese de Doutorado. Programa de Pós-Graduação em Ciência da Computação. Universidade Federal de Campina Grande (UFCG), Paraíba, PB, Brasil. [GS Search]

Moran, J. M. (2007). A educação que desejamos: novos desafios e como chegar lá. Papirus Editora (2th). [GS Search]

Neto, J. V., Barbosa, C., Torres, É. M., \& Estrela, C. (2017). Boxplot: um recurso gráfico para a análise e interpretação de dados quantitativos. Revista Odontológica Do Brasil Central, 26(76), 1-6. 10trieved from http://www.robrac.org.br/seer/index.php/ROBRAC/article/view/1132 [GS Search]

Nikou, S. A., \& Economides, A. A. (2014a). A model for Mobile-based Assessment adoption based on Self-Determination Theory of Motivation. In Interactive Mobile Communication Technologies and Learning (IMCL). doi: 10.1109/IMCTL.2014.7011111 [GS Search]

Nikou, S. A., \& Economides, A. A. (2014b). Acceptance of Mobile-Based Assessment from the perspective of Self-Determination Theory of Motivation. In 14th International Conference on Advanced Learning Technologies Acceptance. doi: 10.1109/ICALT.2014.136 [GS Search]

Nikou, S. A., \& Economides, A. A. (2016). An Outdoor Mobile-Based Assessment Activity: Measuring Students' Motivation and Acceptance. International Journal of Interactive Mobile Technologies, 10(4), 11-17. doi: 10.3991/ijim.v10i4.5541 [GS Search]

Nikou, S. A., \& Economides, A. A. (2017). Mobile-Based Assessment: Integrating acceptance and motivational factors into a combined model of Self-Determination Theory and Technology Acceptance. Computers in Human Behavior, 68, 83-95. doi: 10.1016/j.chb.2016.11.020 [GS Search]

Orji, R., Mandryk, R. L., \& Vassileva, J. (2014). Selecting effective strategies for tailoring persuasive health games to gamer types. doi: 10.1145/2470654.2481341 [ $\underline{\text { GS Search] }}$

Oliveira, C. De., \& Moura, S. P. (2015). TIC’S na Educação: A Utilização das Tecnologias da Informação e Comunicação na Aprendizagem do Aluno. Pedagogia em Ação, 7(1), 75-95. Retrieved from http://periodicos.pucminas.br/index.php/pedagogiacao/article/view/11019

Oliveira, N., \& Siqueira, S. (2018). Entendendo a Motivação para o Uso de um Ambiente Virtual de Aprendizagem: Um Survey com base no Modelo TAM3 e na Teoria da Autodeterminação. In Brazilian Symposium on Computers in Education (Simpósio Brasileiro de Informática na Educação-SBIE). doi: 10.5753/cbie.sbie.2018 [GS Search]

Oliveira, T., \& Martins, M. F. (2011). Literature Review of Information Technology Adoption Models at Firm Level. The Electronic Journal Information Systems Evaluation, 14(1), 110121. Retrieved from http://ejise.com/issue/download.html?idArticle=705 [GS Search]

Parasuraman, A. P., Zeithaml, V. A., \& Berry, L. L. (1988). SERVQUAL: A multiple-item scale for measuring consumer perceptions of service quality. Journal of Retailing, 64(1), 12-40. [GS Search] 
Pasquali, L. (2003). Psicometria teoria dos testes na psicologia e na educação. Petrópolis: Ed. Vozes. [GS Search]

Ramirez-Anormaliza, R., Sabaté, F., \& Guevara-Viejo, F. (2015). Evaluating Student Acceptance Level of E-learning Systems. In International Conference of Education, Research and Innovation. "ICERI2015: Proceedings 8th International Conference of Education, Research and Innovation November 16th-18th (pp. 2393-2399). Retrieved from http://hdl.handle.net/2117/80996 [GS Search]

Reis, E. A., \& Reis, I. A. (2002). Análise Descritiva de Dados. Relatório Técnico do Departamento de Estatística da UFMG. Retrieved from http://www.est.ufmg.br/portal/arquivos/rts/rte0202.pdf [GS Search]

Roca, J. C., \& Gagné, M. (2008). Understanding e-learning continuance intention in the workplace: A self-determination theory perspective. Computers in Human Behavior, 24(4), 1585-1604. doi: 10.1016/j.chb.2007.06.001 [GS Search]

Rogers, E. M. (1995). Diffusion of Innovations: Modifications of a Model for Telecommunications. In: Stoetzer MW., Mahler A. (eds) Die Diffusion von Innovationen in der Telekommunikation. Schriftenreihe des Wissenschaftlichen Instituts für Kommunikationsdienste, vol 17. Springer, Berlin, Heidelberg. doi: https://doi.org/10.1007/978-3-642-79868-9_2 [GS Search]

Ryan, R. M., \& Connell, J. P. (1989). Perceived Locus of Causality and Internalization: Examining Reasons for Acting in Two Domains. Journal of Personality and Social Psychology, 57(5), 749-761. [GS Search]

Ryan, R. M., \& Deci, E. L. (2000a). Intrinsic and Extrinsic Motivations: Classic Definitions and New Directions. Contemporary Educational Psychology, 25(1), 54-67. doi: 10.1006/ceps.1999.1020 [GS Search]

Ryan, R. M., \& Deci, E. L. (2000b). The darker and brighter sides of human existence: basic psychological needs as a unifying concept. Psychological Inquiry, 11(4), 319-338. doi: 10.1207/S15327965PLI1104_03 [GS Search]

Ryan, R. M., Rigby, C. S., \& Przybylski, A. (2006). The Motivational Pull of Video Games : A Self-Determination Theory Approach. Motivation and Emotion, 30(4), 344-360. doi: http://dx.doi.org/10.1007/s11031-006-9051-8 [GS Search]

Serrão, T. et al. (2016). Construção Automática de Redes Sociais Móveis no Ambiente Moodle. Revista Brasileira de Informática na Educação, 24(1), 20-37. doi: 10.5753/RBIE.2016.24.01.20 [GS Search]

Silva, T. S. C., Tedesco, P. C. D. A. R., \& Melo, J. C. B. De. (2014). A importância da motivação dos estudantes e o uso de técnicas de engajamento para apoiar a escolha de jogos no ensino de programação. In XXV Simpósio Brasileiro de Informática na Educação (pp. 11-15). doi: 10.5753/cbie.sbie.2014.11 [GS Search]

Sun, Y., Wang, N., Shen, X., \& Zhang, J. X. (2015). Location information disclosure in locationbased social network services: Privacy calculus, benefit structure, and gender differences. Computers in Human Behavior, 52, 278-292. doi: 10.1016/j.chb.2015.06.006 [GS Search]

Taber, K. S. (2018). The Use of Cronbach's Alpha When Developing and Reporting Research Instruments in Science Education. Research in Science Education, 48(6), 1273-1296. doi:10.1007/s11165-016-9602-2 [GS Search]

Teixeira, E., Medeiros, F. P. A. De, \& Gomes, A. S. (2011). Microblogging como estilo de 
interação e colaboração em Ambientes Virtuais de Ensino e Aprendizagem. In XXII Simpósio Brasileiro de Informática na Educação - XVII WIE. SBIE, Aracaju. doi: 10.5753/cbie.sbie.2011.\%25p [GS Search]

Tornatzky, L. G., Fleischer, M., \& Chakrabarti, A. K. (1990). The process of Tecnology Innovation. Lexington Books. [GS Search]

Venkatesh, V. (2000). Determinants of Perceived Ease of Use: Integrating Control, Intrinsic Motivation, and Emotion into the Technology Acceptance Model. Information Systems Research, 11(4), 342-365. doi: 10.1287/isre.11.4.342.11872 [GS Search]

Venkatesh, V., \& Bala, H. (2008). Technology Acceptance Model 3 and a Research Agenda on Interventions. Decision Sciences, 39(2), 273-315. doi: 10.1111/j.1540-5915.2008.00192.x [GS Search]

Venkatesh, V., \& Davis, F. D. (2000). A Theoretical Extension of the Technology Acceptance Model: Four Longitudinal Field Studies. Management Science, 46(2), 186-204. doi: $\underline{10.1287 / \mathrm{mnsc} .46 .2 .186 .11926}$ [GS Search]

Venkatesh, V., Morris, M. G., Davis, G. B., \& Davis, F. D. (2003). User Acceptance of Information Technology: Toward a Unified View. MIS Quarterly, 27(3), 425. doi: $\underline{10.2307 / 30036540}$ [GS Search]

Vroom, V. H. (1964). Work and Motivation. New York: Wiley. [GS Search]

Wati, Y., \& Koo, C. (2012). Toward Green IS Adoption Behaviors: A Self-Determination Perspective. In 45th Hawaii International Conference on System Sciences (pp. 1207-1216). IEEE. doi: 10.1109/HICSS.2012.598 [GS Search]

Werbach, K., \& Hunter, D. (2012). For the win: How game thinking can revolutionize your business. Wharton Digital Press. [GS Search]

White, R. W. (1959). Motivation reconsidered. Psychological Review, 66, 297-333. [GS Search]

Wohlin, C. (2014). Guidelines for Snowballing in Systematic Literature Studies and a Replication in Software Engineering. In Proceedings of the 18th international conference on evaluation and assessment in software engineering. ACM, 321-330. doi: 10.1145/2601248.2601268 [GS Search]

Wohlin, C. (2016). Second-Generation Systematic Literature Studies using Snowballing. In Proceedings of the 20th International Conference on Evaluation and Assessment in Software Engineering. ACM, 15. doi: 10.1145/2915970.2916006 [GS Search]

Xexéo, J. A. M. (2009). A Medida da Satisfação do Usuário de Sistemas de Informação. Revista de Sistemas de Informação da FSMA, 3, 10-33. Retrieved from http://www.fsma.edu.br/si/edicao3/FSMA_SI_2009_1_Principal_2.html

Xiong, M., Zhao, A., \& Chen, Q. (2014). The Comparison Study on the Motivations of Staffs' Behaviors on Public and Enterprise Social Network: Evidence from China. In International Conference on Advances in Social Networks Analysis and Mining (ASONAM) (pp. 802-807). [GS Search]

Yacci, M. (2000). Interactivity Demystified: A Structural Definition for Distance Education and Intelligent CBT. Educational Technology, 40(4), 5-16. Retrieved from https://www.researchgate.net/publication/241546524_Interactivity_Demystified_A_Structu ral_Definition_for_Distance_Education_and_Intelligent_CBT [GS Search]

Yang, Y., \& Green, S. B. (2011). Coefficient alpha: A reliability coefficient for the 21st 
century? Journal of Psychoeducational Assessment, 29(4), 377-392. doi: $\underline{10.1177 / 0734282911406668}$ [GS Search]

Zanini, A. da S. (2016). Práticas Escolares Mediadas pela Wiki do Moodle: Análise de Aceitação e Percepções dos Estudantes. Dissertação de Mestrado. Programa de Pós-Graduação em Educação. Universidade Federal de Santa Maria (UFSM). [GS Search] 


\section{Apêndice}

A Tabela 6 apresenta os itens do questionário disponibilizado para os alunos. O questionário é composto por 73 questões subdivido em três partes: a primeira referente as questões do modelo TAM3, a segunda referente as questões da teoria da autodeterminação e a terceira com questões extras a fim de compreender melhor o que está faltando no Ambiente Virtual de Aprendizagem para torná-lo mais atrativo para os alunos. Para cada um dos itens da Tabela 6 é necessário indicar o grau de concordância ou discordância para cada uma das afirmativas, de acordo com uma escala Likert de 7 pontos, conforme descrito abaixo:

1. Discordo Totalmente

2. Discordo

3. Discordo Parcialmente

4. Neutro

5. Concordo Parcialmente

6. Concordo

7. Concordo Totalmente

Além destas questões, também é necessário informa qual o tempo médio de uso do Ambiente Virtual de Aprendizagem semanalmente, tendo como respostas as seguintes opções:

1. Só acesso para realizar as tarefas

2. 15 minutos

3. 30 minutos

4. 1 hora

5. 2 horas

6. 3 horas

7. 4 horas ou mais

Tabela 6: Questionário

\begin{tabular}{|c|c|c|}
\hline & Itens & Questões \\
\hline \multirow{14}{*}{ 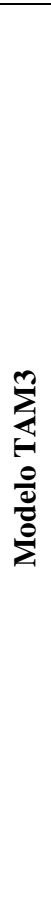 } & PU1 & $\begin{array}{l}\text { O uso do Ambiente Virtual de Aprendizagem melhora o meu desempenho no meu processo de } \\
\text { aprendizagem. }\end{array}$ \\
\hline & PU2 & $\begin{array}{l}\text { O uso do Ambiente Virtual de Aprendizagem aumenta a minha produtividade em relação à } \\
\text { aprendizagem. }\end{array}$ \\
\hline & PU3 & O uso do Ambiente Virtual de Aprendizagem aumenta minha eficácia na minha aprendizagem. \\
\hline & PU4 & Acho que o Ambiente Virtual de Aprendizagem é útil na minha aprendizagem. \\
\hline & PEOU1 & Minha interação com o Ambiente Virtual de Aprendizagem é clara e compreensível \\
\hline & PEOU2 & Interagir com o Ambiente Virtual de Aprendizagem não exige muito do meu esforço mental. \\
\hline & PEOU3 & Eu acho o Ambiente Virtual de Aprendizagem fácil de usar. \\
\hline & PEOU4 & Eu acho fácil fazer com que o Ambiente Virtual de Aprendizagem faça o que eu quero que ele faça. \\
\hline & SN1 & $\begin{array}{l}\text { Pessoas que influenciam meu comportamento acham que eu devo usar o Ambiente Virtual de } \\
\text { Aprendizagem. }\end{array}$ \\
\hline & SN2 & Pessoas que são importantes para mim acham que eu devo usar o Ambiente Virtual de Aprendizagem. \\
\hline & SN3 & Os tutores estão sendo úteis no uso do Ambiente Virtual de Aprendizagem. \\
\hline & SN4 & A universidade apoia o uso do Ambiente Virtual de Aprendizagem. \\
\hline & VOL1 & Uso o Ambiente Virtual de Aprendizagem voluntariamente. \\
\hline & VOL2 & Os professores não exigem que eu use o Ambiente Virtual de Aprendizagem. \\
\hline
\end{tabular}




\begin{tabular}{|c|c|}
\hline VOL3 & $\begin{array}{l}\text { Embora possa ser útil, o uso do Ambiente Virtual de Aprendizagem não é obrigatório para minha } \\
\text { formação. }\end{array}$ \\
\hline IMG1 & $\begin{array}{l}\text { Colegas da minha universidade que usam o Ambiente Virtual de Aprendizagem têm mais influência do } \\
\text { que aqueles que não usam. }\end{array}$ \\
\hline IMG2 & $\begin{array}{l}\text { Colegas da minha universidade que usam o Ambiente Virtual de Aprendizagem têm um perfil de } \\
\text { renome. }\end{array}$ \\
\hline IMG3 & Dominar o Ambiente Virtual de Aprendizagem é sinal de status na universidade. \\
\hline REL1 & Na minha área, o uso de um Ambiente Virtual de Aprendizagem é importante. \\
\hline REL2 & Na minha área, o uso de um Ambiente Virtual de Aprendizagem é relevante. \\
\hline REL3 & O Uso do Ambiente Virtual de Aprendizagem é pertinente a várias tarefas da minha aprendizagem. \\
\hline OUT1 & $\begin{array}{l}\text { A qualidade do resultado que recebo no fim de cada atividade realizada no Ambiente Virtual de } \\
\text { Aprendizagem é alta. }\end{array}$ \\
\hline OUT2 & Não tenho problemas com a qualidade dos resultados gerados pelo Ambiente Virtual de Aprendizagem. \\
\hline OUT3 & Avalio os resultados gerados pelo Ambiente Virtual de Aprendizagem como excelentes. \\
\hline RES1 & $\begin{array}{l}\text { Não tenho dificuldade em contar para os colegas sobre os resultados das tarefas realizadas no Ambiente } \\
\text { Virtual de Aprendizagem. }\end{array}$ \\
\hline RES2 & Posso contar para os colegas os resultados de se utilizar um Ambiente Virtual de Aprendizagem. \\
\hline RES3 & Os resultados do uso de um Ambiente Virtual de Aprendizagem são visíveis para mim. \\
\hline RES4 & $\begin{array}{l}\text { Teria dificuldade em explicar porque usar o Ambiente Virtual de Aprendizagem pode ser benéfico ou } \\
\text { não. }\end{array}$ \\
\hline BI1 & Supondo que eu tenha acesso ao Ambiente Virtual de Aprendizagem, pretendo usá-lo. \\
\hline BI2 & Dado que eu tenha acesso ao Ambiente Virtual de Aprendizagem, prevejo que o usaria. \\
\hline BI3 & Pretendo utilizar o Ambiente Virtual de Aprendizagem nos próximos semestres. \\
\hline CSE1 & $\begin{array}{l}\text { Seria capaz de concluir minhas tarefas no Ambiente Virtual de Aprendizagem mesmo se não houvesse } \\
\text { ninguém por perto para me dizer o que fazer. }\end{array}$ \\
\hline CSE2 & $\begin{array}{l}\text { Seria capaz de concluir minhas tarefas no Ambiente Virtual de Aprendizagem somente com o recurso } \\
\text { de ajuda integrado no próprio ambiente. }\end{array}$ \\
\hline CSE3 & $\begin{array}{l}\text { Seria capaz de concluir minhas tarefas no Ambiente Virtual de Aprendizagem caso alguém me dissesse } \\
\text { e/ou mostrasse como fazer primeiro. }\end{array}$ \\
\hline CSE4 & $\begin{array}{l}\text { Seria capaz de concluir minhas tarefas no Ambiente Virtual de Aprendizagem se já tivesse utilizado } \\
\text { um sistema semelhante. }\end{array}$ \\
\hline PEC1 & Tenho controle sobre o uso do Ambiente Virtual de Aprendizagem. \\
\hline PEC2 & Tenho os recursos necessários para usar o Ambiente Virtual de Aprendizagem. \\
\hline PEC3 & $\begin{array}{l}\text { Dados os recursos, oportunidades e conhecimento necessários, seria fácil para mim usar o Ambiente } \\
\text { Virtual de Aprendizagem. }\end{array}$ \\
\hline PEC4 & O Ambiente Virtual de Aprendizagem não é compatível com os outros sistemas utilizados por mim. \\
\hline CPLAY & Como você se caracteriza em relação ao Uso do Ambiente Virtual de Aprendizagem? \\
\hline CPLAY1 & Espontâneo \\
\hline CPLAY2 & Criativo \\
\hline CPLAY3 & Divertido \\
\hline CPLAY4 & Trivial \\
\hline CANX1 & Usar o Ambiente Virtual de Aprendizagem não me assusta nem um pouco. \\
\hline CANX2 & Usar o Ambiente Virtual de Aprendizagem me deixa nervoso(a). \\
\hline CANX3 & Usar o Ambiente Virtual de Aprendizagem me faz sentir desconfortável. \\
\hline CANX4 & Usar o Ambiente Virtual de Aprendizagem me faz sentir receoso(a). \\
\hline
\end{tabular}




\begin{tabular}{|c|c|c|}
\hline & ENJ1 & Usar o Ambiente Virtual de Aprendizagem é agradável. \\
\hline & ENJ2 & O processo atual de usar o Ambiente Virtual de Aprendizagem é prazeroso. \\
\hline & ENJ3 & Eu me divirto usando o Ambiente Virtual de Aprendizagem. \\
\hline \multirow{7}{*}{ } & EXT & Uso o Ambiente Virtual de Aprendizagem porque devo usar. \\
\hline & INTROJ1 & $\begin{array}{l}\text { Uso o Ambiente Virtual de Aprendizagem porque eu quero que os outros alunos pensem que sou } \\
\text { inteligente. }\end{array}$ \\
\hline & INTROJ2 & $\begin{array}{l}\text { Uso o Ambiente Virtual de Aprendizagem porque eu quero que o professor pense que sou um bom } \\
\text { aluno. }\end{array}$ \\
\hline & IDENT1 & Uso o Ambiente Virtual de Aprendizagem porque eu quero aprender coisas novas. \\
\hline & IDENT2 & Uso o Ambiente Virtual de Aprendizagem porque eu acho importante para minha formação. \\
\hline & INTRINS & Uso o Ambiente Virtual de Aprendizagem porque eu gosto. \\
\hline & DESMOT & Não tenho vontade de usar o Ambiente Virtual de Aprendizagem. \\
\hline \multirow{17}{*}{ 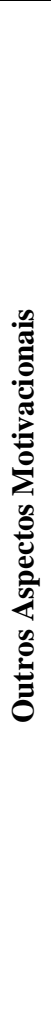 } & & Eu me sentiria mais motivado em utilizar o Ambiente Virtual de Aprendizagem se... \\
\hline & ASPECT1 & ... eu tivesse uma boa interação com o professor. \\
\hline & ASPECT2 & ... eu tivesse uma boa interação com o tutor. \\
\hline & ASPECT3 & ... eu pudesse interagir mais com os meus colegas de classe. \\
\hline & ASPECT4 & ... tivesse intensa troca de mensagens no Ambiente. \\
\hline & ASPECT5 & ... o Ambiente estivesse associado a uma rede social. \\
\hline & ASPECT6 & ... tivesse profissionais de mercado participando das interações, mesmo que esporadicamente. \\
\hline & ASPECT7 & ... as avaliações de interações fossem publicadas para todos do curso (ou para todos da universidade). \\
\hline & ASPECT8 & ... os melhores trabalhos fossem disponibilizados na universidade. \\
\hline & ASPECT9 & ... tivesse mais materiais multimídias. \\
\hline & ASPECT10 & ... tivesse notícias atualizadas constantemente. \\
\hline & ASPECT11 & ... tivesse jogos para apoiar o processo de aprendizagem. \\
\hline & ASPECT12 & ... tivesse desafios valendo ponto extra. \\
\hline & ASPECT13 & ... tivesse um placar para os alunos de destaque. \\
\hline & ASPECT14 & $\begin{array}{l}\text {... tivesse recompensa, como distribuição de medalhas, para cada atividade realizada de acordo com as } \\
\text { regras estabelecidas. }\end{array}$ \\
\hline & ASPECT15 & ... tivesse feedback de professores e/ou tutores sobre o meu desempenho em cada atividade avaliativa. \\
\hline & ASPECT16 & ... pudesse curtir a postagem de algum colega. \\
\hline
\end{tabular}

